San Jose State University

SJSU ScholarWorks

Master's Theses

Master's Theses and Graduate Research

Fall 2015

\title{
Characterization of Gut Associated Circulating Invariant Natural Killer T Cells (iNKT) in Chronic Inflammation of the Intestine
}

Venus Allahyarzadeh

San Jose State University

Follow this and additional works at: https://scholarworks.sjsu.edu/etd_theses

\section{Recommended Citation}

Allahyarzadeh, Venus, "Characterization of Gut Associated Circulating Invariant Natural Killer T Cells (iNKT) in Chronic Inflammation of the Intestine" (2015). Master's Theses. 4619.

DOI: https://doi.org/10.31979/etd.cb4u-cb22

https://scholarworks.sjsu.edu/etd_theses/4619

This Thesis is brought to you for free and open access by the Master's Theses and Graduate Research at SJSU ScholarWorks. It has been accepted for inclusion in Master's Theses by an authorized administrator of SJSU ScholarWorks. For more information, please contact scholarworks@sjsu.edu. 
CHARACTERIZATION OF GUT ASSOCIATED CIRCULATING INVARIANT NATURAL KILLER T CELLS (iNKT) IN CHRONIC INFLAMMATION OF THE INTESTINE

\author{
A Thesis \\ Presented to \\ The Faculty of the Department of Biological Sciences \\ San José State University \\ In Partial Fulfillment \\ of the Requirements for the Degree \\ Master of Science
}

By

Venus Allahyarzadeh

December 2015 
(C) 2015

Venus Allahyarzadeh

ALL RIGHTS RESERVED 
The Designated Thesis Committee Approves the Thesis Titled

CHARACTERIZATION OF GUT ASSOCIATED CIRCULATING INVARIANT NATURAL KILLER T CELLS (iNKT) IN CHRONIC INFLAMMATION OF THE INTESTINE

by

Venus Allahyarzadeh

APPROVED FOR THE DEPARTMENT OF BIOLOGICAL SCIENCES

SAN JOSÉ STATE UNIVERSITY

December 2015
Dr. Tzvia Abramson
Department of Biological Studies
Dr. Kenneth Youngman
Department of Biological Sciences
Dr. Katherine Wilkinson
Department of Biological Sciences 


\section{ABSTRACT \\ CHARACTERIZATION OF GUT ASSOCIATED CIRCULATING INVARIANT NATURAL KILLER T CELLS (iNKT) IN CHRONIC INFLAMMATION OF THE INTESTINE}

by Venus Allahyarzadeh

The incidence of chronic intestinal diseases such as Crohn's disease (CD), ulcerative colitis (UC), and celiac disease is steadily rising in pediatric patients in the United States. Although there is an influx of helper T cells to the gastrointestinal (GI) tract in these diseases, the immunopathologic mechanisms of specific $\mathrm{T}$ cell subsets are not clearly understood and diagnosis between these diseases is difficult. We hypothesized that the frequency of specific subsets of circulating invariant natural killer $\mathrm{T}$ (iNKT) cells and their surface trafficking receptor (TR) phenotype indicate location and degree of inflammation in patients and further help to distinguish between these chronic intestinal diseases. We performed a multi-color flow cytometry analysis on peripheral blood (PB) $\mathrm{CD}^{-}$and $\mathrm{CD}^{+}$iNKT cells in pediatric patients in the non-active and active disease states with CD $(n=6), U C(n=7)$, celiac disease $(n=2)$ and healthy donors (HDs) $(n=7)$. The average frequency of circulating $\mathrm{CD}^{-}$and $\mathrm{CD}^{+}$iNKT cells in patients with non-active and active disease states was significantly increased in comparison to HD. A greater percentage of the CD8- iNKT cells in UC patients expressed the gut-homing TRs $\alpha 4 \beta 7$ and GRPR15 indicative of cell migration to the large intestine. In sum, circulating iNKT cells were elevated in patients with these chronic intestinal diseases. Screening specific subsets of iNKTs may provide a more efficient form of distinguishing between $\mathrm{UC}, \mathrm{CD}$ and Celiac disease and may potentially be used as a complementary approach to monitoring disease activity or therapeutic efficacy in pediatric patients. 


\section{ACKNOWLEDGEMENTS}

This work is the result of collaborative efforts involving San José State University, Kaiser Permanente in Santa Clara, and Stanford University. I would like to thank the members of my committee Dr. Youngman and Dr. Wilkinson for their help with finalizing this paper and taking the time to provide valued feedback. I would especially like to thank my thesis adviser, Dr. Tzvia Abramson, for her guidance and mentorship over the past few years. None of this work would have been possible without her motivation and encouragement. This work was also made possible by the patient samples that were provided by our collaborative work with Kaiser Permanente and the time and commitment of Dr. Oren Abramson and Dr. Anthony Wong, to whom I also owe many thanks. I could not have compiled this work without the help of my peers in the Abramson lab, namely Nicole Tarlton as well as my undergraduate assistant Christopher Qualls. Lastly, I would like to extend gratitude to Nicole Lazaraus and the entire Butcher lab at Stanford for their help with this work and Lusijah Rott for her invaluable assistance with the flow cytometer machines.

Thank you to everyone whose blood, sweat and tears went into completing this thesis, literally. The largest thank you is owed to my parents and their unfailing support in all of my endeavors. 


\section{TABLE OF CONTENTS}

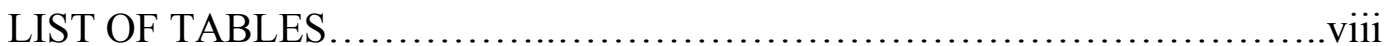

LIST OF FIGURES ......................................................

CHAPTER I: OVERVIEW OF THE RESEARCH PROJECT ...................1

CHAPTER II: CHARACTERIZATION OF GUT ASSOCIATED CIRCULATING INVARIANT NATURAL KILLER T CELLS (iNKT) IN CHRONIC INFLAMMATION OF THE INTESTINE...................................4

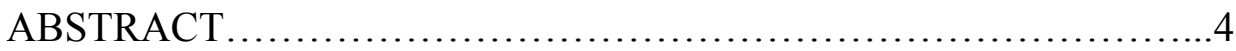

INTRODUCTION................................................5

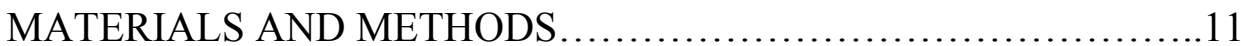

Ethical considerations....................................11

Lymphocyte separation from whole blood.....................12

Monoclonal antibodies for flow cytometry phenotypic analysis...12

Cell staining and flow cytometry analysis.....................13

Statistical analysis..................................... 14

Experimental design and subjects..........................14

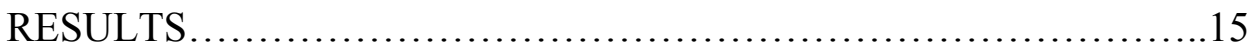

Characterization of two distinct populations of iNKT cells.......16

Frequency of circulating $\mathrm{CD}^{+}{ }^{+}$iNKT cells in patients with $\mathrm{UC}, \mathrm{CD}$, and celiac disease.................................................18

Frequency of circulating iNKT cell subsets in patients with $\mathrm{UC}, \mathrm{CD}$, and celiac disease.................................18

Expression of trafficking receptors on the surface of subsets of iNKT cell populations...................................23 
Frequency of double positive iNKT subsets expressing $\alpha 4 \beta 7$, CLA, or GPR15 ...................................... 28

DISCUSSION........................................................... 32

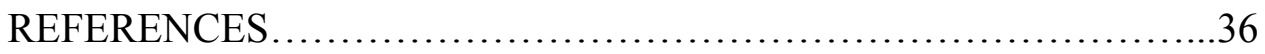

CHAPTER III: FUTURE EXPLORATIONS...................................40 


\section{LIST OF TABLES}

TABLE 1: List of pediatric UC, CD, and celiac disease patients and sample information......................................................... 


\section{LIST OF FIGURES}

FIGURE 1: Isolating iNKT subsets by flow cytometry................17

FIGURE 2: Frequency of circulating iNKT cells $\ldots \ldots \ldots \ldots \ldots \ldots \ldots \ldots . \ldots 18$

FIGURE 3: Frequency of iNKT cell populations.......................20

FIGURE 4: Single molecule TR analysis on iNKT cell populations......24

FIGURE 5: Double positive TR analysis on iNKT cell populations.......29 


\section{CHAPTER I: OVERVIEW OF THE RESEARCH PROJECT}

Inflammatory bowel disease (IBD), comprising Crohn's disease (CD) and ulcerative colitis (UC), and celiac disease, is a type of autoimmune disease characterized by chronic inflammation of the gastrointestinal tract (GI). Previous work in our lab focused on a rare B cell precursor population of plasmablasts, specifically their increase in UC. We focused this project on all three diseases and asked if analyzing circulating blood immune cells can be used to make a differential diagnosis. In particular, we aimed to compare a rare innate immune cell population (iNKT cells) in pediatric patients with one of these three diseases to healthy donors (HD).

Though both children and adults may be diagnosed with these diseases, we concentrated on pediatric patients for multiple reasons. Unlike adults, pediatric patients diagnosed with a recent onset of these chronic diseases are less likely to be affected by other comorbidities and long-term medication use. The risk for lymphomas in IBD and celiac disease due to constant mucosal damage from a young age as well as the use of immunomodulators or anti-tumor necrosis agents is unclear and a large concern to patients and their families. And although IBD and celiac disease are on the rise in the United States, pediatric research is lacking in comparison to research on the adult population.

There is limited immunopathological information concerning these diseases. For example, although the relationship between celiac disease and its trigger, gluten, is well described, the precise etiology of IBD conditions is not understood. Abnormalities have been described in genetically predisposed patients, such as increased counts of B and T cell lymphocytes to the mucosal regions causing inflammation to the GI tract (1). The 
migration of these lymphocytes is a highly controlled process influenced by trafficking receptors (TRs) expressed on the surface of lymphocytes that work in conjunction and direct the cells to their destination organs (2). Our primary focus was iNKT cells, which have been implicated in all three of these chronic diseases (3). We hypothesized that the percent of circulating iNKT cells would be increased in the peripheral blood of patients with an active disease state and express an altered TR phenotype indicative to gut homing cells. Using multi-color flow cytometry, we analyzed TRs in conjunction on the surface of peripheral blood iNKT cells. Our research aimed to investigate whether iNKT frequency in the blood would reflect the type of chronic intestinal disease and the disease activity.

We observed an increase in circulating iNKTs in pediatric patients with $\mathrm{UC}, \mathrm{CD}$ and celiac disease and found, with UC in particular, an increase in CD8 ${ }^{-}$iNKT cells expressing the large-intestinal TRs $\alpha 4 \beta 7$ and GPR15. Our data indicated that a CD8 ${ }^{-}$ iNKT subset increases and migrates to the gut via $\alpha 4 \beta 7$ and GPR15 during the active disease states, especially in UC. These results suggest a specific immunological function of CD8 ${ }^{-}$iNKT cells expressing $\alpha 4 \beta 7$ and GPR15 for pediatric patients during active stages of chronic gut diseases. Combining this knowledge with previous work in our lab regarding the increase of plasmablasts in UC patients may provide significant progress toward fully characterizing the immune response of these diseases. Our research has identified two distinct populations of iNKT cells where the CD8- iNKT cells seem to play a more significant role in the active patients, especially in UC. Further characterization of cell surface receptors, which would identify more subsets of these iNKT cells, may allow us to identify which specific subsets of iNKT cells are altered during different 
stages of these diseases and where they are migrating based on specific TRs. These data may provide a screening tool to provide a complimentary approach to monitoring disease activity and therapeutic efficacy, which would increase the quality of life for patients with this life-long disease and provide the possibility of targeted treatments in the future. 


\title{
CHAPTER II
}

\section{Characterization of Gut-Associated Circulating Invariant Natural Killer T Cells (INKT) in Chronic Inflammation of the Intestine}

Venus Allahyarzadeh ${ }^{1}$, Christopher Qualls ${ }^{2}$, Tzvia Abramson ${ }^{3 *}$

\begin{abstract}
Chronic inflammatory diseases of the gut, such as Crohn's disease (CD), ulcerative Colitis (UC) and celiac disease are on the rise, especially in pediatric patients. These diseases share many epidemiological and clinical characteristics. Currently, invasive procedures, such as colonoscopies and general blood tests for inflammation, are the most accurate way to determine differential diagnosis due to differences in location and variable pattern of inflammation between the diseases. It is well documented that the immune responses in these diseases are abnormal. However, cellular trafficking receptor expression on primary immune responders in $\mathrm{UC}, \mathrm{CD}$ and celiac disease is understudied, making it difficult to differentiate between these chronic inflammatory conditions. iNKT cells are a group of natural killer $\mathrm{T}$ cells that were recently suggested to be associated with autoimmune and inflammatory diseases and have a role in IBD models in mice. However, their role in humans is understudied. We hypothesized that iNKT cells arise differentially in patients experiencing chronic inflammatory conditions and that
\end{abstract}

\footnotetext{
${ }^{1}$ Graduate student in the department of biological sciences at San Jose State University.

${ }^{2}$ Undergraduate assistant in the department of biological sciences at San Jose State University at the time of this study.

${ }^{3}$ Principle Investigator in the department of biological sciences, One Washington Square, San Jose, CA 95192 (Phone: 408-924-4872; Fax: 408-924-4840; E-mail: tzvia.abramson@,sjsu.edu).

Funding: This work was supported by funds from CSUPERB, from NIH SC3GM100854.

Disclosures: The authors have no conflicts of interest to disclose.
} 
trafficking receptor (TR) characteristics may predict the anatomical location of the lesions and disease severity.

Using multi-color flow cytometric analysis, we compared circulating CD8 ${ }^{-}$and $\mathrm{CD} 8{ }^{+}$iNKT populations and their trafficking receptor phenotype in pediatric patients with $\mathrm{CD}, \mathrm{UC}$, and celiac disease with active and non-active stages of disease, and in healthy donors (HD). Our results indicated that both active and non-active patients diagnosed with UC, CD or celiac disease had significantly increased percentages of both $\mathrm{CD}^{-}$and $\mathrm{CD} 8^{+}$iNKT populations. Further analysis of trafficking receptors in these populations showed an increased percentage of these cells expressing the large intestine trafficking phenotype $\alpha 4 \beta 7^{+} \mathrm{GPR} 15^{+}$, especially the CD8 ${ }^{-}$iNKT cells. Further, the $\alpha 4 \beta 7^{+} \mathrm{GPR} 15^{+} \mathrm{CD} 8^{-}$iNKT population increased most in the active UC patient.

The findings of this study suggest that the analysis of circulating iNKT cells in patients with chronic gut conditions can be a non-invasive tool that provides information on disease flare and the presence of lesions in the large intestine of patients with chronic inflammatory diseases of the gut. Analysis of iNKT cells throughout the process of inflammation may provide additional accurate diagnostic information on the course of these inflammatory diseases and perhaps reduce the need for the invasive approaches.

\section{Introduction}

Celiac disease and the two main forms of inflammatory bowel disease (IBD), ulcerative colitis (UC) and Crohn's disease (CD), are three chronic inflammatory diseases of the gastrointestinal tract (GI). All three diseases are most common in developed countries. The root cause of these chronic diseases is unknown; however, certain risk factors have been identified such as the environment, previous medical conditions, vaccinations, and 
genetic predispositions (4). In the United States, approximately 1.4 and 1.8 million people suffer from IBD and celiac disease, respectively. However, this statistic does not account for misdiagnosis or unreported cases $(5,6)$.

Although both adults and children suffer from these diseases, pediatric patients have a more severe onset at diagnosis and, over the past decade, the incidence of all three diseases has steadily increased in pediatric patients in America $(4,7,8)$. Clinical manifestations of IBD and celiac disease are unspecific symptoms that include abdominal pain and diarrhea, creating difficulties for clear diagnosis. These symptoms vary depending on which region of the gastrointestinal (GI) tract is affected and the severity of the inflammation $(9,10)$. Patients with CD suffer from ulcers throughout the GI tract that appear patchy but penetrative, whereas ulcers in UC patients are specific to the colon and have a smooth, continuous and superficial appearance. Celiac disease results in villous atrophy in the upper and lower intestine, resulting in a scalloped pattern of the intestinal $\operatorname{tract}(11,12)$.

Currently, the main method of diagnosis is identifying the morphological and anatomic differences between ulcers and lesions by an invasive endoscopy (13). Additional general tests of inflammation, such as for C-reactive protein (CRP) and erythrocyte sedimentation rate (ESR), are used to supplement the diagnosis and monitoring of the disease inflammation (14). There is no singular, efficient method of diagnosis for these diseases and diagnostic inconsistencies are very common, which makes a common method of diagnosis difficult to obtain (15).

Treatments available for patients with chronic gut diseases are also nonspecific since the precise target for the disease is unclear. Current treatments, such as 
immunosuppressive drugs and corticosteroids, are primarily designed to address the inflammation and prevent future relapses $(14,16)$. IBD patients are treated with corticosteroids or immunosuppressive therapy for rapid anti-inflammatory relief; however, long-term use is discouraged due to many side effects, including infections and neurological defects (14). Maintenance treatments commonly include drugs that inhibit the general inflammatory cytokine tumor necrosis factor (TNF)- $\alpha$. Since TNF- $\alpha$ is a main cytokine secreted by many activated immune cells in response to microbial pathogens (17), patients treated with anti-TNF- $\alpha$ drugs are vulnerable to recurring infections. Additionally, prolonged use of anti-TNF- $\alpha$ drugs renders many patients unresponsive with very few treatment options and with a small, but significant, risk for lymphoma (18). In contrast, celiac disease patients generally resolve symptoms by following a gluten free diet; however, a proportion of patients become refractory (7).

There is accumulating information on differential immunological responses between UC and CD (19), which are currently being explored for more specific diagnosis and treatment. For example, patients with $\mathrm{CD}$ display $\mathrm{T}$ cell mediated responses, in particular Th1 and Th17 responses, which secrete inflammatory cytokines and recruit to the gut an array of cytotoxic immune cells such as neutrophils, macrophages and natural killer cells. Those immune cells contribute to the tissue destruction and lesions in the intestinal mucosa (20). This specific increase of Th17 cells in the peripheral blood and gut during CD inflammatory response is currently being explored as a way to preferentially diagnose and treat $\mathrm{CD}$. For example, clinical trials for anti-CCR9 drugs, which inhibit adhesion molecules that inappropriately recruit Th17 to the gut, have been shown to reduce IBD patient symptoms with fewer side effects than current treatments 
$(21,22)$. In contrast, UC patients display elevated Th2 and B cell responses. In 2012, Tarlton et al. showed a rise of circulating plasmablasts, a premature activated form of B cells, which express a specific $\alpha 4 \beta 7$ gut-homing phenotype in severe UC patients (23). Thus, they suggest that rise in plasmablasts could be an immediate blood indicator for a newly diagnosed UC or recent UC flare in the colon. Celiac disease is unique from IBD because its antigenic trigger has long been identified as deamidated gluten. Mucosal Th1 cells in patients with genetically altered HLA-DQ2, and DQ8 molecules are inappropriately activated by gliadin and glutenins. This skewed Th1 response results in an over production of inflammatory cytokines (24). Recent findings describe an enrichment of a natural killer phenotype of inner epithelial T lymphocytes in conjunction with interferon-gamma (IFN- $\gamma$ ) production during the inflammatory response and might suggest a role for rare lymphocyte T cell subsets, such as iNKT cells $(25,26)$.

Current studies involving these three diseases draw attention to invariant natural killer T (iNKT) cells, a thymus derived lymphocyte population which specifically expresses the T cell receptor (TCR) V $\alpha 24-J \alpha 18$ and are activated by CD-1d molecules $(27,28)$. Furthermore, different subsets of iNKT cells, such as iNKT 17 cells that differ from Th17 cells but similarly produce IL-17 (29), have been recognized to serve specific functions during the immune response, which are dictated by a particular combination of cell surface markers $(30,31,32,33)$. Flow cytometry analysis indicates that iNKT cells secrete pro and anti-inflammatory cytokines, such as IFN- $\gamma$ and IL-4 based on their expression of CD4 and CD8 $(34,35)$. The $\mathrm{CD}^{+}{ }^{+}$iNKT populations secrete cytokines similar to a Th2 immune response where the CD8 iNKT cells induce a Th1 type immune response. The cytokine profile secreted by iNKT cells is influenced by antigen activation 
and initiates different immune responses that mimic responses dictated by regulatory or helper $\mathrm{T}$ cells (36). Therefore, cell surface phenotype may identify the specific subset of iNKT cells and reflect their cytokine profile, which may indicate the kind of immune response generated by any specific regulatory T cells.

Under homeostatic conditions, circulating iNKT cells comprise only $0.02-0.2 \%$ of $\mathrm{CD}^{+} \mathrm{T}$ cells in both mice and humans. Studies in mice show that this frequency is significantly altered in several autoimmune diseases including UC, CD, and celiac disease, as well as other diseases such as multiple sclerosis and diabetes $(37,38,39)$. Additionally, a study on germ-free mice that were more susceptible to colitis infection had a higher percentage of circulating iNKT cells compared to wild type mice (40). In contrast, studies specifically on refractory celiac disease have shown a deficiency of iNKT cells in the gut $(41,42)$ that may be attributed to a problem with iNKT cytokine secretion, either with iNKT cells already present in the intestine, or the migration of iNKT cells to the intestine.

The dysregulation of cellular migration is a leading cause of autoimmune diseases and is implicated in the onset of IBD and Celiac disease (43). Cellular migration to specific tissues is determined by chemokine receptors expressed on the surface of lymphocytes that facilitate the migration towards their respective tissue ligands and bind to adhesion molecules expressed on tissue vasculature $(44,45)$. Determining the fate and function of specific lymphocytes during a disease response is a promising approach to creating successful therapies. In particular, drugs are being designed to inhibit specific gut cytokines to block leukocyte trafficking and reduce inflammation in the tissue (46, 47). For example, drugs undergoing clinical trials that are designed to inhibit cytokines 
and adhesion molecules responsible for trafficking immune cells to the intestine, such as CCR9, $\alpha 4 \beta 7$, and anti $\alpha 4$, have shown promise; however, more research is required before clinical application $(48,22)$.

Previous studies have established an increase in the frequency of the mucosal vascular addressin cell adhesion molecule 1 (MaADCAM-1) in the gut during IBD, which attracts lymphocytes expressing the TR $\alpha 4 \beta 7$, the counter partner for MaADCAM1 (49). GPR15 is an orphan G-protein coupled receptor that was originally discovered as a co-receptor for the HIV virus (50). Recent studies of mouse colitis models have shown that when GPR15 expression is blocked or inhibited in regulatory $\mathrm{T}$ cells, there is increased inflammation in the large intestine, which indicates the presence of GPR15 expressing lymphocyte migration to the colon $(51,52)$. However, trafficking of $\mathrm{T}$ lymphocytes, which express GPR15, to the large intestine is understudied in humans, and may have a significant role in chronic gut immunity.

A proportion of patients with IBD and celiac disease also experience skin irritation and allergies. Non-gut TRs expressed on lymphocytes may serve to detect extraintestinal complications. For example, the cutaneous lymphocyte antigen (CLA) is often expressed by circulating B and T cells in IBD patients that have symptoms such as joint inflammation or liver damage $(53,54)$. Studies of these TRs on the surface of circulating iNKT populations in these chronic gut diseases at various stages could provide insight into disease activity and immune response.

In this study, we hypothesized that frequency and cell surface phenotype of circulating iNKT cells would reflect disease state and location of inflammation in patients with IBD and celiac disease. Through multi-color flow cytometry analysis, we 
characterized two distinct populations of iNKT cells that differed in expression of CD8. We analyzed the frequency of these two subsets of circulating iNKT cells and their surface trafficking receptors (TR) between pediatric IBD and celiac disease patients during non-active and active disease states in comparison to healthy donors (HD).

The data from this study showed an alteration of the frequency of circulating iNKT cells in patients with chronic gut diseases compared to HDs. We observed an increased percentage of both $\mathrm{CD}^{-}$and $\mathrm{CD}^{+}{ }^{\mathrm{iNKT}}$ subsets in the peripheral blood of non-active and active patients compared to HDs. The migration patterns for $\mathrm{CD}^{-}$and $\mathrm{CD} 8^{+}$iNKT subsets are distinct based on TR expression and disease activity. Only the CD8 ${ }^{-}$iNKT population had an increase in the expression of TRs $\alpha 4 \beta 7$ and GPR15, which likely indicates cell migration to the large intestine.

The characterization of specific iNKT subsets in patients with chronic gut diseases may provide a complementary approach to disease diagnosis and monitoring as well as provide information on the chronic nature of the diseases and extraintestinal complications. The ability to characterize the immune response of these diseases in a non-invasive way is extremely important for patients' quality of life. Furthermore, understanding the immunopathology of specific cell subsets will allow for the development of targeted therapies.

\section{Materials and Methods}

\section{Ethical considerations}

This study was conducted with IRB approval from Kaiser Permanente in Santa Clara, CA (IRB\# CN-09AWong-01-H) and San José State University in San Jose, CA (IRB 
\#F1402014). All blood samples obtained for use in this study were obtained with informed consent.

Lymphocyte separation from whole blood

Heparinized peripheral blood samples were obtained by a licensed phlebotomist using a venipuncture technique from the different donor populations: $10 \mathrm{ml}$ from each pediatric UC patient $(n=6), C D$ patient $(n=4)$, celiac patient $(n=2)$ and healthy donor $(n=7)$. The peripheral blood mononuclear (PBMC) layer was separated and extracted by processing blood with Ficoll (Histopaque-1077, Sigma-Aldrich, St. Louis, MO) density gradient centrifugation. The PBMC layer was washed twice with Hank's Balanced Salt Solution (HBSS) without $\mathrm{Ca}^{++} / \mathrm{Mg}^{++}$and then re-suspended in staining buffer (1X PBS with $2 \%$ FCS and $0.1 \%$ sodium azide). Cells were blocked for a minimum of ten minutes with normal human serum and normal goat serum (Gibco, Invitrogen by Life Technologies, Carlsbad, CA), and then cells were stained with antibodies and acquired by flow cytometer.

\section{Monoclonal antibodies for flow cytometry phenotypic analysis}

The primary conjugated antibodies used were mouse anti-human TCR Va24-Ja18 PECy7

(clone 6B11, Biolegend, San Diego, CA), mouse anti-human CD16 APC Cy7 (clone

3G8, BD Biosciences, San Jose, CA), mouse anti-human CD8 Alexa Fluor 700 (clone

RPA-T8, BD Biosciences, San Jose, CA), mouse anti-human CD3 V500 (clone SP34-2, BD Biosciences, San Jose, CA), and mouse anti-human $\alpha 4 \beta 7$ PE (courtesy of Butcher Lab at Stanford University from EDM Millipore, Billerica, MA).

The primary unconjugated antibodies used were mouse anti-human GPR15 (clone 367902, R\&D Systems, Minneapolis, MN) conjugated in house to goat $F(a b ’)_{2}$ anti- 
mouse Pacific Blue (Invitrogen, Carlsbad, CA), and Biotin rat anti-human CLA (cutaneous lymphocyte antigen, Clone HECA-452, BD Biosciences, San Jose, CA) conjugated in house with Streptavidin Qdot 565 (Invitrogen, Carlsbad, CA)

\section{Cell staining and flow cytometry analysis}

PBMCs at a concentration of $2 \times 10^{6}$ per donor sample were stained with the antibodies mentioned above. First, cells were stained with primary anti-human GPR15 antibody, washed, and followed with secondary anti-mouse Pacific Blue labeling. After a second wash, cells were blocked with normal mouse serum (NMS, Santa Cruz Biotechnology, Santa Cruz, CA). Next, a cocktail of the primary conjugated antibodies was applied to the cells. Subsequently, cells were stained with primary anti-CLA biotin antibody, washed, and labeled with Streptavidin Qdot565. Lastly, cells were fixed in a 1\% paraformaldehyde solution and washed a final time before re-suspension in staining buffer.

Alongside the donor sample, to account for background staining, "n-1" controls with $2 \times 10^{6}$ PBMCs were prepared for the two primary antibodies labeled in house (addition of Pacific Blue without GPR15 and Streptavidin Qdot565 without CLA) and the pre-conjugated iNKT marker (TCR V $\alpha 24-J \alpha 18)$, which included all other antibodies except that of each control. Other than these changes, controls and donor samples were treated and prepared in the same way. All samples were acquired using a BD Biosciences LSRII flow cytometer (Butcher lab at Stanford University) using FACSDiva software.

Flow cytometry data were analyzed using FlowJo software (Tree Star Inc., Ashland, OR). iNKT population and TR gate placement were determined by the "n-1" 
controls or comparison of the peaks for positive and negative staining populations. Unspecific binding was accounted for by subtracting any faint positive signals in the iNKT, CLA, and GPR15 control samples.

\section{Statistical Analysis}

Each experimental group was compared to the HD group and significant differences between the pairs were determined by the student's $t$ test ${ }^{4}$. Consideration of statistical significance was based on a value of $p \leq 0.05$. In a previous paper our lab determined there is no relationship between age, gender, drug treatment and response levels by Wilcoxon and regression F test (23).

Experimental design and subjects

IBD and celiac disease patients were scored on disease severity. Diagnosis of UC, CD and celiac is determined by use of clinical lab tests, endoscopy, histopathology, and radiology findings. Disease activity was assessed using the Pediatric Ulcerative Colitis Activity Index (PUCAI), the Crohn's Disease Activity Index (CDAI), and Celiac Disease Marsh Score, and patients were classified into "active" or "non-active" groups (Table 1). Patients gave consent to participate in this study to the Pediatric Gastroenterologists at Kaiser Permanente in Santa Clara, CA. Blood samples were drawn from patients before anti-TNF- $\alpha$ infusion therapy or during routine blood-work.

A total of 2 celiac disease, $7 \mathrm{UC}$, and $7 \mathrm{CD}$ patient samples were collected. The samples included 5 males and 8 females ranging in ages from 8 to 18 years old.

\footnotetext{
${ }^{4}$ All statistical methods were reviewed and approved by Martina Bremmer, a statistician in the SJSU Department of Math.
} 
TABLE 1. List of pediatric $\mathrm{UC}, \mathrm{CD}$, and celiac disease patients and sample information

\begin{tabular}{|c|c|c|c|c|c|c|c|c|c|c|}
\hline Sample & Disease & PUCAI Score & CDAI Score & Marsh Score & CRP & ESR & Patient Group & Age (years) & Gender $(M / F)$ & Treatment \\
\hline$\S 1$ & UC & 0 & & & 0.5 & 26 & Non-Active & 12 & $\mathrm{~F}$ & ${ }^{* *}$ Imuran \\
\hline$\$_{2}$ & UC & 5 & & & 0.1 & 10 & Non-Active & 12 & $\mathrm{~F}$ & ${ }^{*}$ Remicade/ ${ }^{* *} \mid$ muran \\
\hline$\$ 3$ & UC & 0 & & & 0.1 & 8 & Non-Active & 12 & $\mathrm{~F}$ & ${ }^{*}$ Remicade/ ${ }^{* *}$ Imuran \\
\hline$\$ 4$ & UC & 0 & & & 0.5 & 17 & Non-Active & 12 & $\mathrm{~F}$ & ${ }^{*}$ Remicade $/{ }^{*}{ }^{*}$ Imuran \\
\hline$\varphi 5$ & UC & 2.5 & & & 0 & 22 & Non-Active & 10 & $M$ & ${ }^{*}$ Remicade \\
\hline$\varphi_{6}$ & UC & 0 & & & 0.1 & 33 & Non-Active & 10 & $M$ & None \\
\hline 7 & UC & 25 & & & 0.1 & 9 & Active & 15 & $\mathrm{~F}$ & $* * * 5 A S A$ \\
\hline$\xi 8$ & $C D$ & & 0 & & 0.4 & 14 & Non-Active & 17 & $\mathrm{~F}$ & ${ }^{*}$ Remicade \\
\hline$\xi 9$ & $C D$ & & 0 & & 0.1 & 14 & Non-Active & 17 & $\mathrm{~F}$ & ${ }^{*}$ Remicade \\
\hline $\mathrm{f}_{10}$ & $\mathrm{CD}$ & & 0 & & 0.2 & 11 & Non-Active & 11 & $\mathrm{~F}$ & ${ }^{*}$ Remicade \\
\hline${ }^{f} 11$ & $C D$ & & 0 & & 0.2 & 23 & Non-Active & 11 & $\mathrm{~F}$ & ${ }^{*}$ Remicade \\
\hline 12 & $\mathrm{CD}$ & & 27.5 & & 1.7 & 41 & Active & 16 & $\mathrm{~F}$ & *anti- $\alpha 4 \beta 7$ \\
\hline$x_{13}$ & $\mathrm{CD}$ & & 17.5 & & 1.3 & 36 & Active & 14 & $M$ & None \\
\hline$x_{14}$ & $C D$ & & 5 & & 0.4 & 11 & Active & 14 & $M$ & ${ }^{*}$ Remicade \\
\hline 15 & Celiac & & & $3 B$ & & & Active & 9 & $\mathrm{~F}$ & None \\
\hline 16 & Celiac & & & $3 A$ & & & Active & 13 & $M$ & None \\
\hline
\end{tabular}

TABLE 1. Patient Group is based on PUCAI (range 0-100, active disease state $>10$ ), CDAI (range 0-76, active disease state $>5$ ), or Marsh Score (range stage $0-4$, active disease state $>$ stage 2 ) of the patients.

*Biological Therapies: anti-TNF- $\alpha$ monoclonal antibodies, Remicade, anti- $\alpha 4 \beta 7$

**Immunomodulators: Imuran

$* * *$ Anti-inflammatory agents: 5 -aminosalicylic acid (5ASA)

$\S, \varphi, \xi, £, ¥$ Samples with the same symbol were obtained from the same patient at separate time points.

M-male, F-female, ESR-erythrocyte sedimentation rate, CRP-C-reactive protein

Healthy donors selected to participate in this study were not afflicted by IBD or celiac disease or any other illness for a minimum of one month before their blood sample was taken. A total of $7 \mathrm{HD}$ samples were taken from 3 males and 4 females ranging from 3 donors 18-25 years old, 3 donors $25-30$, and 1 donor $31+$ year old. One sample per healthy donor was used.

\section{Results}

These experiments were designed to investigate sub populations of iNKT cells and determine whether they provide information on chronic intestinal disease severity, and may be used to distinguish between various chronic intestinal conditions. 


\section{Characterization of two distinct populations of iNKT cells}

The iNKT cell population is mostly characterized by a CD1d tetramer and $\mathrm{T}$ cell receptor beta (TCR- $\beta$ ), which can make it difficult to discriminate from other natural killer T cells. Here, we use a monoclonal antibody specific to the TCR shared only by iNKT cells, TCR Va24-Ja18 (iNKT marker) (27).

Two iNKT cell populations were gated from the extracted PBMC (Fig. 1A-E): $\mathrm{CD}^{+}{ }^{+} \mathrm{CD} 8^{-} \mathrm{CD} 16^{+} \mathrm{TCR}$ V $\alpha 24-\mathrm{J} \alpha 18^{+}\left(\mathrm{CD}^{+} \mathrm{CD}^{-}\right.$iNKT cells) and $\mathrm{CD} 3^{+} \mathrm{CD} 8^{+} \mathrm{CD} 16^{+} \mathrm{TCR}$ V $\alpha 24-J \alpha 18^{+}\left(\mathrm{CD}^{+}{ }^{+} \mathrm{CD} 8^{+}\right.$iNKT cells). PBMCs were first gated on lymphocytes (Fig. 1A) then on single cells (Fig. 1B). Then, single lymphocytes positive for the thymocyte marker CD3 were identified and separated into CD8 positive and negative populations (Fig. 1C). Each of these populations was further gated for positive expression of CD16, and TCR Va24-Ja18, the iNKT marker (Fig. 1D and 1E). Flow cytometry data

confirmed the presence of two distinct iNKT populations where the $\mathrm{CD} 8^{+}(1.4 \% \mathrm{p}=0.02)$ iNKT population was approximately twice as dense as the $\mathrm{CD}^{-}(0.5 \%)$ iNKT population gated from $\mathrm{CD}^{+}$lymphocytes (Fig. 1F). 

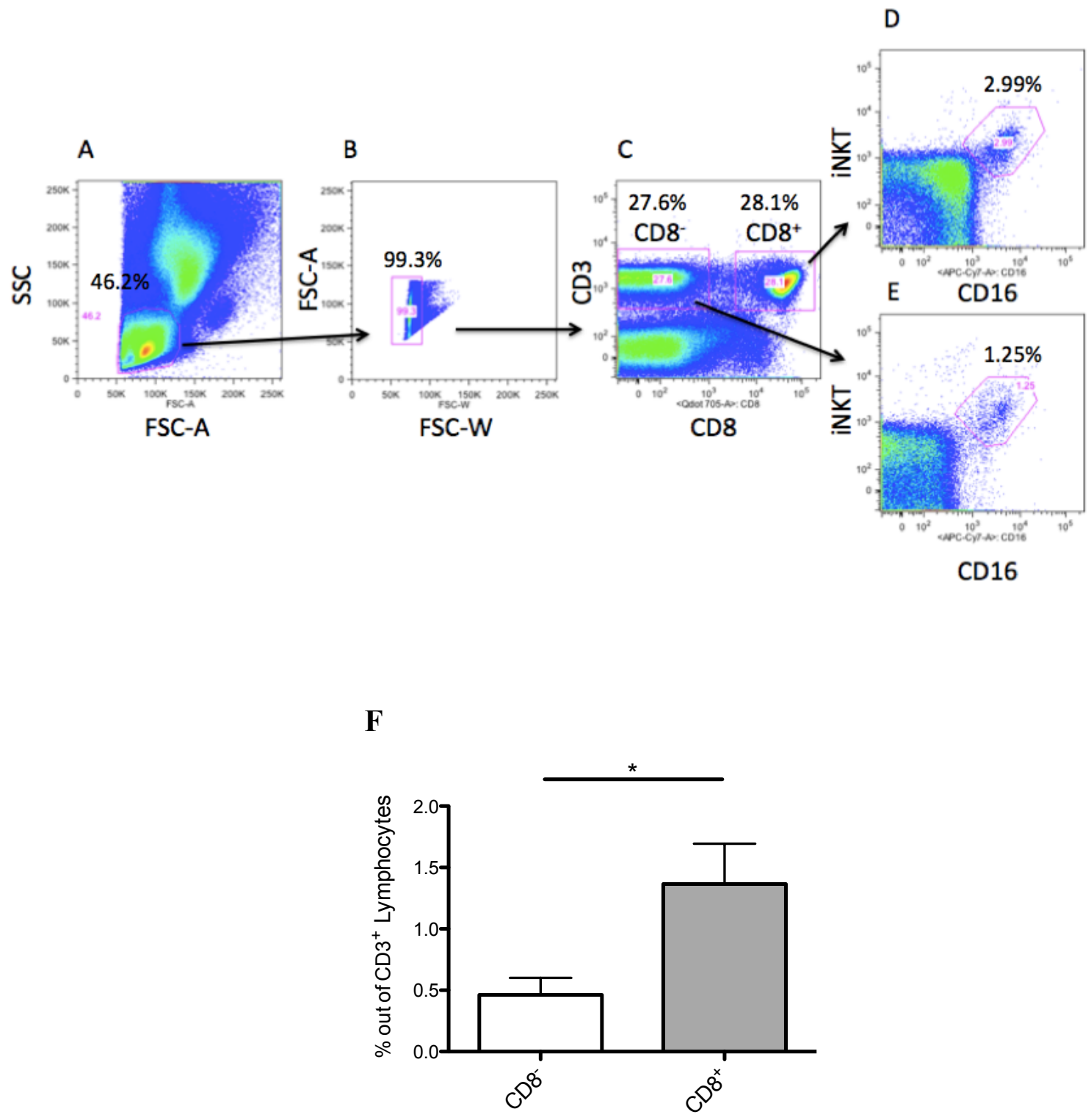

FIGURE 1. Isolating iNKT subsets by flow cytometry. Representative flow cytometry data showing the gating strategy to isolate two distinct iNKT populations (sample 9 in Table 1). (A) Lymphocytes gated from PBMC's. (B) Singlets were separated from doublets. (C) Lymphocytes were gated into $\mathrm{CD}^{+} \mathrm{T}$ cells and $\mathrm{CD}^{-} \mathrm{T}$ cells on all cells that are of thymocyte origin which are $\mathrm{CD}^{+}$cells. (D) The iNKT population gated from $\mathrm{CD}^{+}{ }^{+} \mathrm{CD} 8^{+}$cells. (E) The iNKT population gated from $\mathrm{CD} 3{ }^{+} \mathrm{CD} 8^{-}$cells. (F) Percent of $\mathrm{CD}^{-}$and $\mathrm{CD}^{+}{ }^{+}$iNKT subsets out of $\mathrm{CD}^{+}$lymphocytes in all patients. ${ }^{*} \mathrm{p}<0.05$; $\mathrm{t}$-test. 
Frequency of circulating $C D 3^{+}$iNKT cells in patients with $U C, C D$ and celiac disease

We first wanted to look at all circulating iNKT cells in order to determine if there was an altered frequency in patients compared to HDs. Percentages of all $\mathrm{CD}^{+}{ }^{+}$iNKT cells were pooled for patients with each disease and HDs. There was a significant increase in circulating $\mathrm{CD}^{+}{ }^{+}$iNKT cells in $\mathrm{UC}(3.3 \% \mathrm{p}=0.01), \mathrm{CD}(2.2 \% \mathrm{p}=0.0001)$, and celiac disease $(2.5 \% \mathrm{p}=0.03)$ patients compared to HDs $(0.3 \%)$. However, no differences were observed between the pooled samples of the various diseases (Fig. 2).

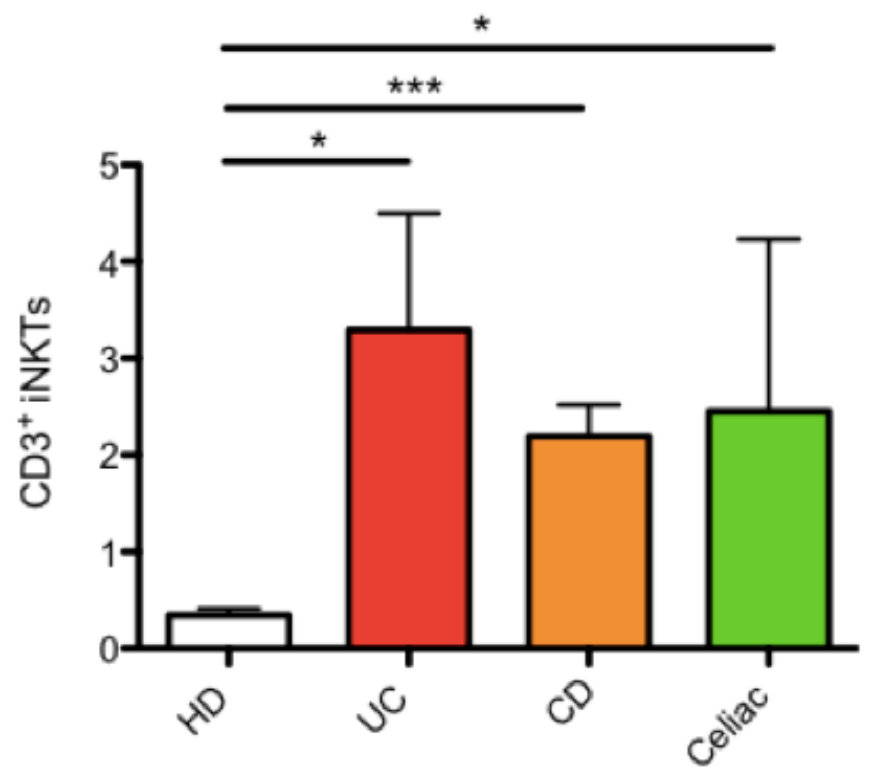

FIGURE 2. Frequency of circulating iNKT cells. Percentage of $\mathrm{CD}^{+}{ }^{+}$iNKT cells out of total lymphocytes in $\mathrm{UC}(\mathrm{n}=7), \mathrm{CD},(\mathrm{n}=7)$ and celiac patients $(\mathrm{n}=2)$ compared to HD's $(\mathrm{n}=7) . * \mathrm{p}<0.05, * * \mathrm{p}<0.005, * * * \mathrm{p}<0.0005$; t-test.

Frequency of circulating iNKT cell subsets in patients with $U C, C D$, and celiac disease In order to test if a specific circulating iNKT cell subset is altered during various states of chronic intestinal inflammation, we compared the frequency of CD8 ${ }^{-}$and $\mathrm{CD} 8^{+}$iNKT subsets in non-active and active patients to HDs. All patients were analyzed according to the description in Figure 1A-E and the flow cytometry CD8 ${ }^{-}$and $\mathrm{CD} 8^{+}{ }^{-}$NKT populations 
of each disease state are shown (Fig. 3A-3F). Disease status was organized according to the clinical score as described in the Table 1. The analyzed data were distributed into patients that are non-active or active regardless of the disease type. The percentages of $\mathrm{CD} 8^{-}$or $\mathrm{CD}^{+}{ }^{~}$ iNKT populations were compared between non-active patients, active patients and HDs. There was a significant increase in the mean percentage of $\mathrm{CD}^{-}$iNKT cells in non-active $(0.88 \% \mathrm{p}=0.01)$ and active patients $(0.6 \% \mathrm{p}=0.035)$ in comparison to HDs $(0.05 \%)$ (Fig. 3G). Similarly, the mean percent of CD $8^{+}$iNKT cells in non-active $(1.62 \% \mathrm{p}=0.01)$ and active patients $(2.02 \% \mathrm{p}=0.025)$ was significantly increased compared to HDs $(0.16 \%)$ (Fig. $3 \mathrm{H})$. The mean percentage of CD8 ${ }^{-}$iNKT population was moderately, but not significantly, higher in non-active patients than active patients. In the $\mathrm{CD}^{+}$iNKT population the percent increase seemed to correlate with disease activity. The data suggested these two iNKT subsets both have a role during different stages of disease. No significant differences were observed for $\mathrm{CD}^{+}$and $\mathrm{CD} 8^{-}$populations of iNKT cells between active and non-active patients (Fig. 3G and H). 


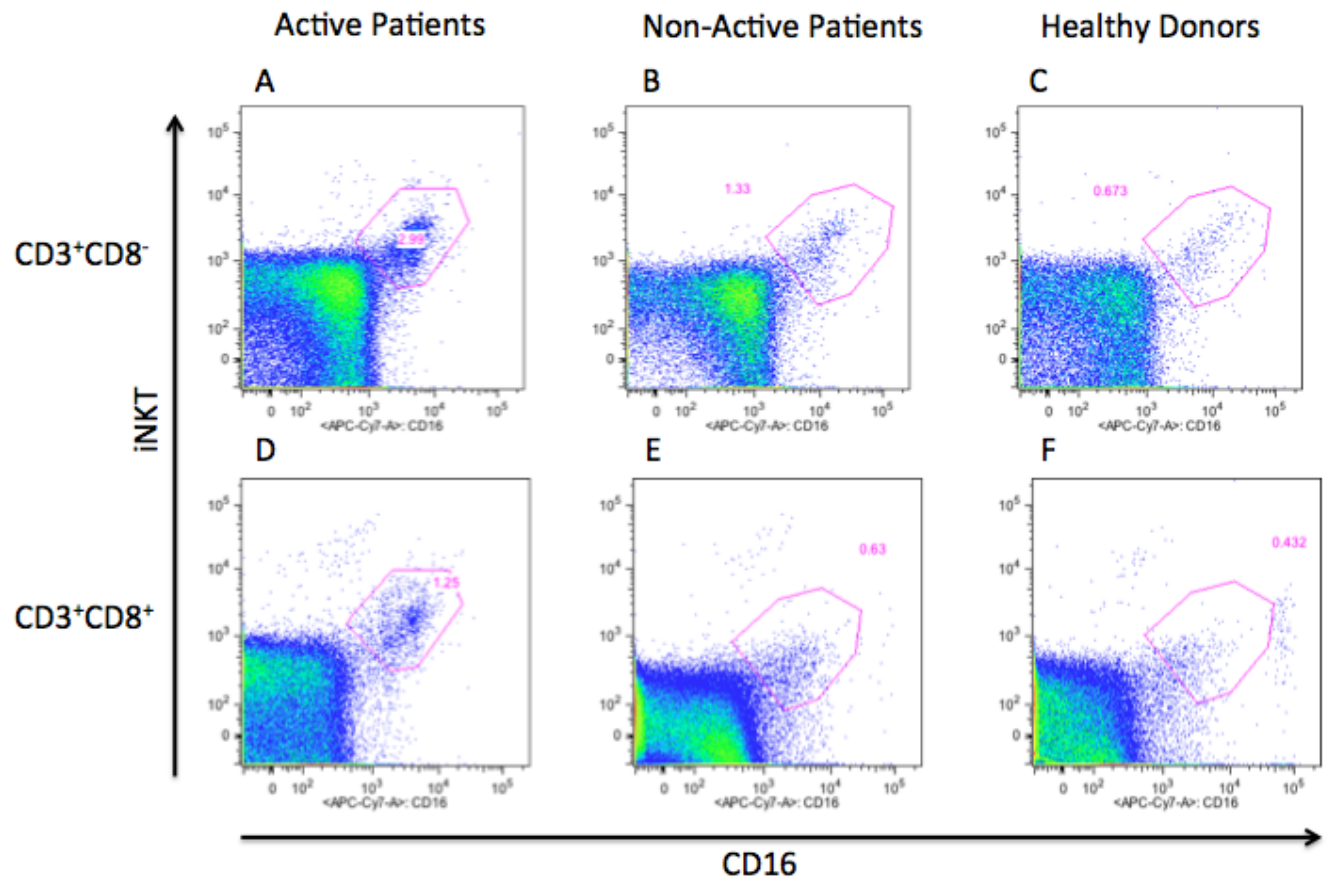

FIGURE 3. Frequency of iNKT cell populations. (A-C) Representative flow cytometry comparison of CD8 ${ }^{-}$iNKT population (D-F) and CD8 ${ }^{+}$iNKT between active patients $(n=9)$, non-active patients $(n=7)$ and HDs $(n=7)$.

CD8 iNKT

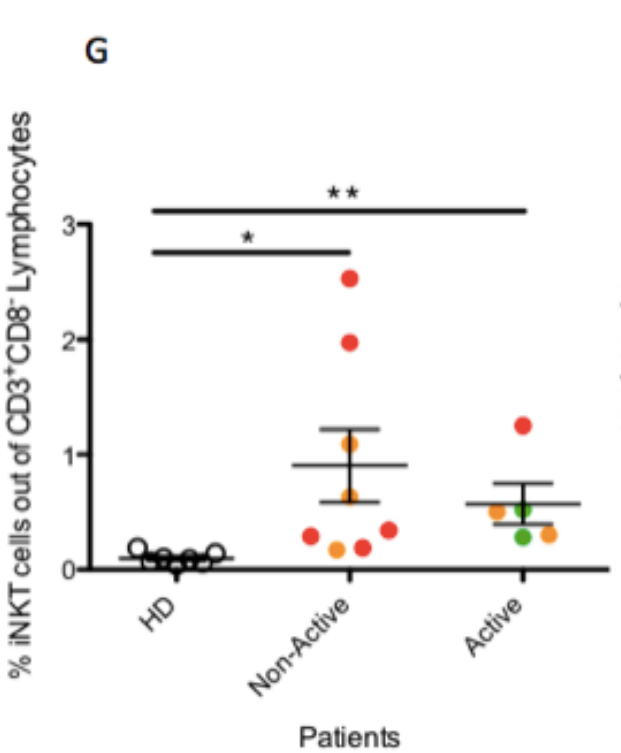

$\mathrm{CD}^{+}{ }^{+} \mathrm{iNKT}$

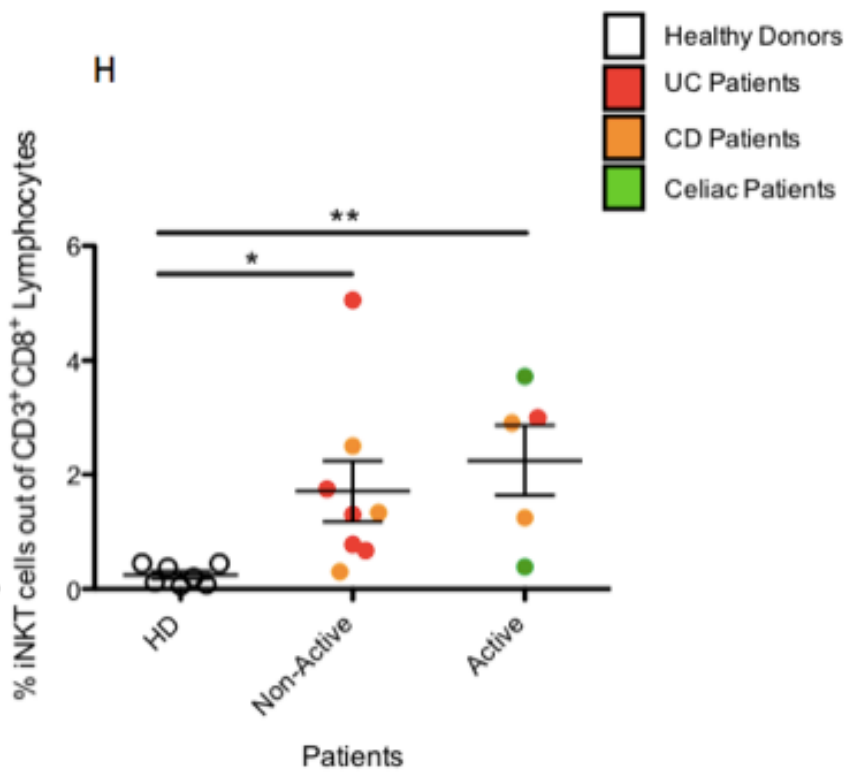




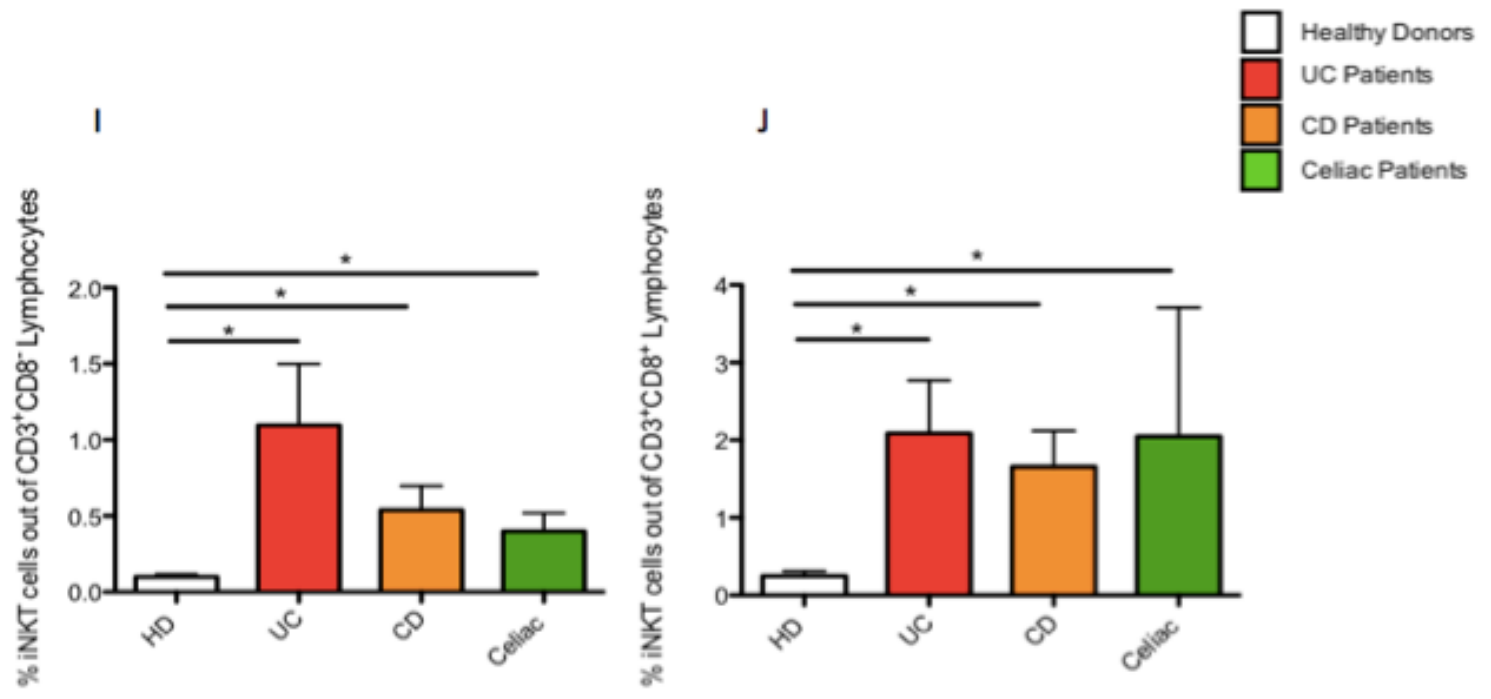

FIGURE 3. Continued. (G) Percentage of peripheral blood CD8 ${ }^{-}$iNKT (H) and CD $8^{+}$ iNKT cells in HDs, non-active and active state patients. (I) Percentage of circulating $\mathrm{CD}^{-}$and $(\mathbf{J}) \mathrm{CD}^{+}$iNKT cells in HD patients with $\mathrm{UC}(\mathrm{n}=7), \mathrm{CD}(\mathrm{n}=7)$ and celiac disease $(\mathrm{n}=2) . * \mathrm{p}<0.05, * * \mathrm{p}<0.005$; t-test, ND indicates no data. 

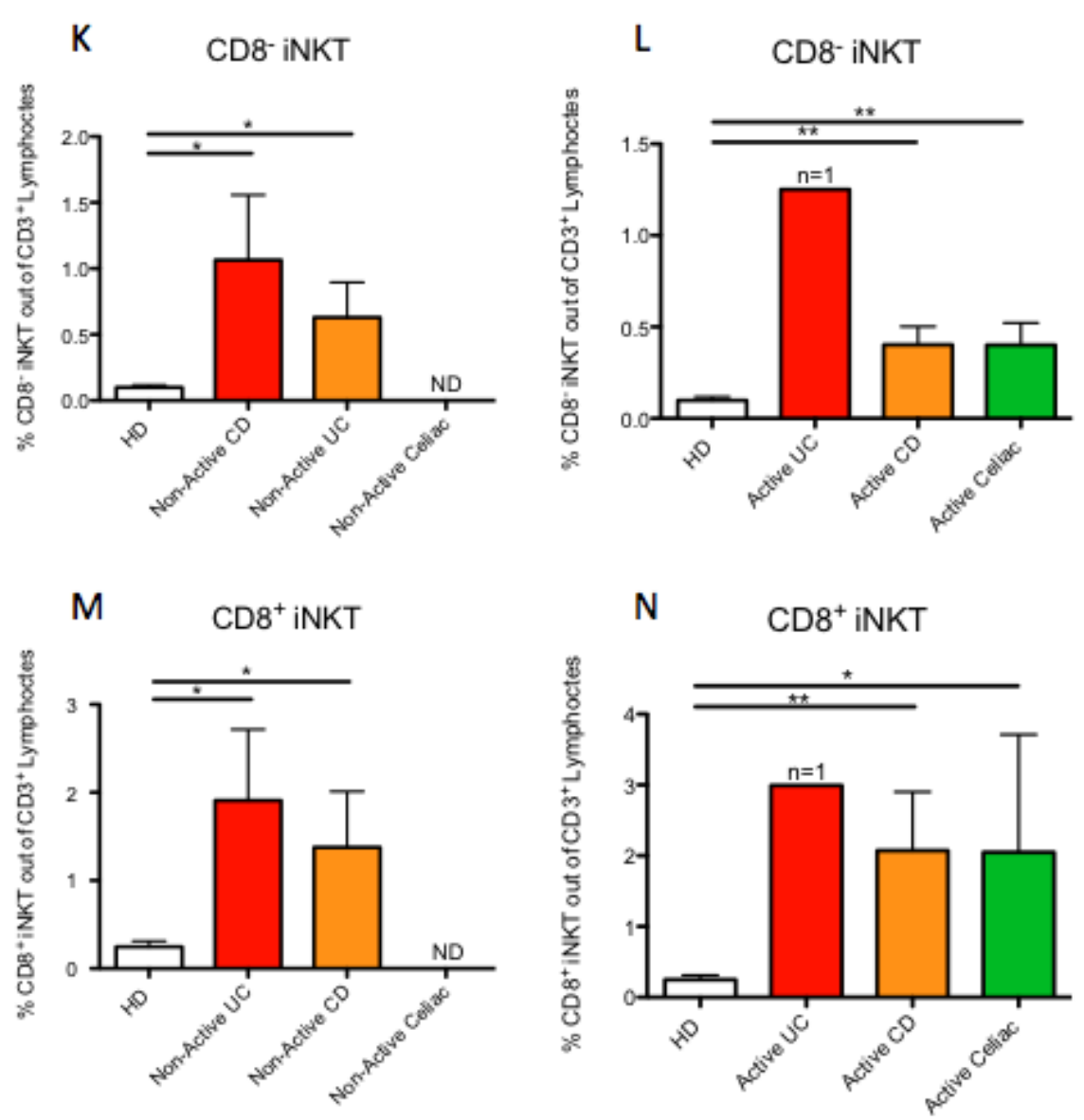

FIGURE 3. Continued. (K) Percentage of CD8 iNKT cells in HD ( $\mathrm{n}=7)$ and nonactive patients $(\mathrm{n}=7)(\mathbf{L})$ and active patients $(\mathrm{n}=9)$. (M) Percentage of $\mathrm{CD} 8^{+}$iNKT cells in $\mathrm{HD}(\mathrm{n}=7)$ and non-active patients $(\mathrm{n}=7)(\mathbf{N})$ and active patients $(\mathrm{n}=9) .{ }^{*} \mathrm{p}<0.05, * *$ $\mathrm{p}<0.005$; t-test, ND indicates no data.

We then asked if there was a specific alteration in the percentages of iNKT cells in patients with $\mathrm{UC}, \mathrm{CD}$, or Celiac disease. To test that, we analyzed the patient samples according to the diagnosed disease and pooled them together regardless of disease activity (score). Interestingly, there was a significant increase in the frequency of both circulating iNKT subsets in patients with all three diseases compared to HDs. The CD8population of iNKT cells was slightly higher in $\mathrm{UC}$ patients $(1.1 \% \mathrm{p}=0.02)$ compared to HDs $(0.09 \%)$; $\mathrm{CD}(0.54 \% \mathrm{p}=0.01)$ and celiac disease $(0.4 \% \mathrm{p}=0.02)$ were not as high as UC (Fig. 3I). Although significantly higher than HDs (0.2\%), the increase in $\mathrm{CD}^{+}{ }^{+}$iNKT 
population between $\mathrm{UC}(2.1 \% \mathrm{p}=0.01), \mathrm{CD}(1.7 \% \mathrm{p}=0.04)$, and celiac disease $(2.05 \%$ $\mathrm{p}=0.03)$ did not vary significantly (Fig. 3J).

To test if the iNKT population varies within each disease in respect to the disease status (score), we compared the percent of circulating CD8 ${ }^{-}$and $\mathrm{CD} 8^{+}$iNKT cells in the patients with non-active and active disease states specifically in $\mathrm{UC}, \mathrm{CD}$, and celiac disease (no non-active celiac). The frequency of $\mathrm{CD}^{-}$iNKT cells in non-active UC $(1.1 \% \mathrm{p}=0.04)$ and $\mathrm{CD}(0.63 \% \mathrm{p}=0.03)$ were significantly higher compared to HDs (0.09\%)(Fig. 3K). Similarly compared to HDs, the percent of CD8 ${ }^{-}$iNKT cells was increased in active $\mathrm{CD}(0.4 \% \mathrm{p}=0.003)$ and active celiac disease $(0.4 \% \mathrm{p}=0.005)$ patients (Fig. 3L). Although less prominent, the percentage of $\mathrm{CD} 8^{+}$iNKT cell population increased in non-active UC $(1.9 \% \mathrm{p}=0.03)$ and non-active $\mathrm{CD}(1.4 \% \mathrm{p}=0.02)$ compared to HD's $(0.2 \%)$ (Fig. 3M), as well as for active CD $(2.1 \% \mathrm{p}=0.002)$ and celiac disease $(2.1 \% \mathrm{p}=0.04)($ Fig. $3 \mathrm{~N})$. Interestingly, the $\mathrm{CD}$ patient data showed a marginally higher percentage in non-active patients where the opposite was observed in the CD8 ${ }^{-}$iNKT population, reiterating the suggestion of a difference in the roles between these two iNKT subsets.

\section{Expression of trafficking receptors on the surface of subsets of iNKT cell populations} Next we analyzed the surface expression of trafficking receptors (TRs) on both iNKT populations to determine if there is a mechanism of cell migration of these subsets to the intestine. We compared surface expression of the gut-homing TR $\alpha 4 \beta 7$, the novel largeintestine TR GPR15, as well as the extraintestinal cutaneous lymphocyte antigen (CLA) on $\mathrm{CD} 8^{-}$and $\mathrm{CD} 8^{+}$iNKT cells. Our aim was to detect any differential TR expression in 
respect to disease type and disease severity. Figures $4 \mathrm{~A}-\mathrm{H}$ present the gating strategies applied to each of the TRs.
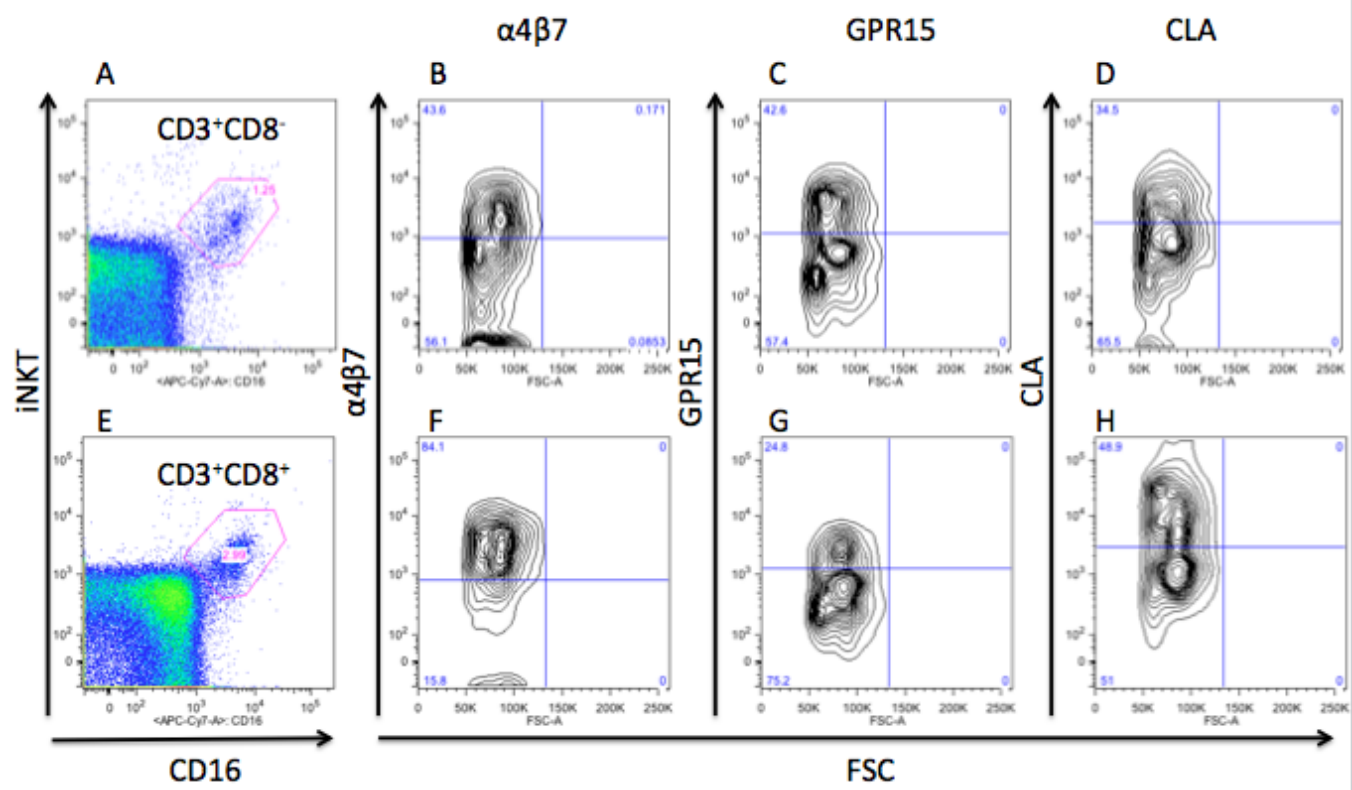

FIGURE 4. Single Molecule TR Analysis on iNKT cell populations. Representative flow cytometry gating of single TRs (sample 9 in Table 1). (A) Single TRs were gated on brightest positive population from both $\mathrm{CD}^{+}{ }^{+} \mathrm{CD} 8^{-}(\mathbf{E})$ and $\mathrm{CD} 3^{+} \mathrm{CD} 8^{+}$iNKT subsets on non-active patients, active patients, and HDs. Single TR of interest is in upper left quadrant of contour plots for (B, F) $\alpha 4 \beta 7,(\mathbf{C}, \mathbf{G})$ CLA and (D, H) GPR15. 

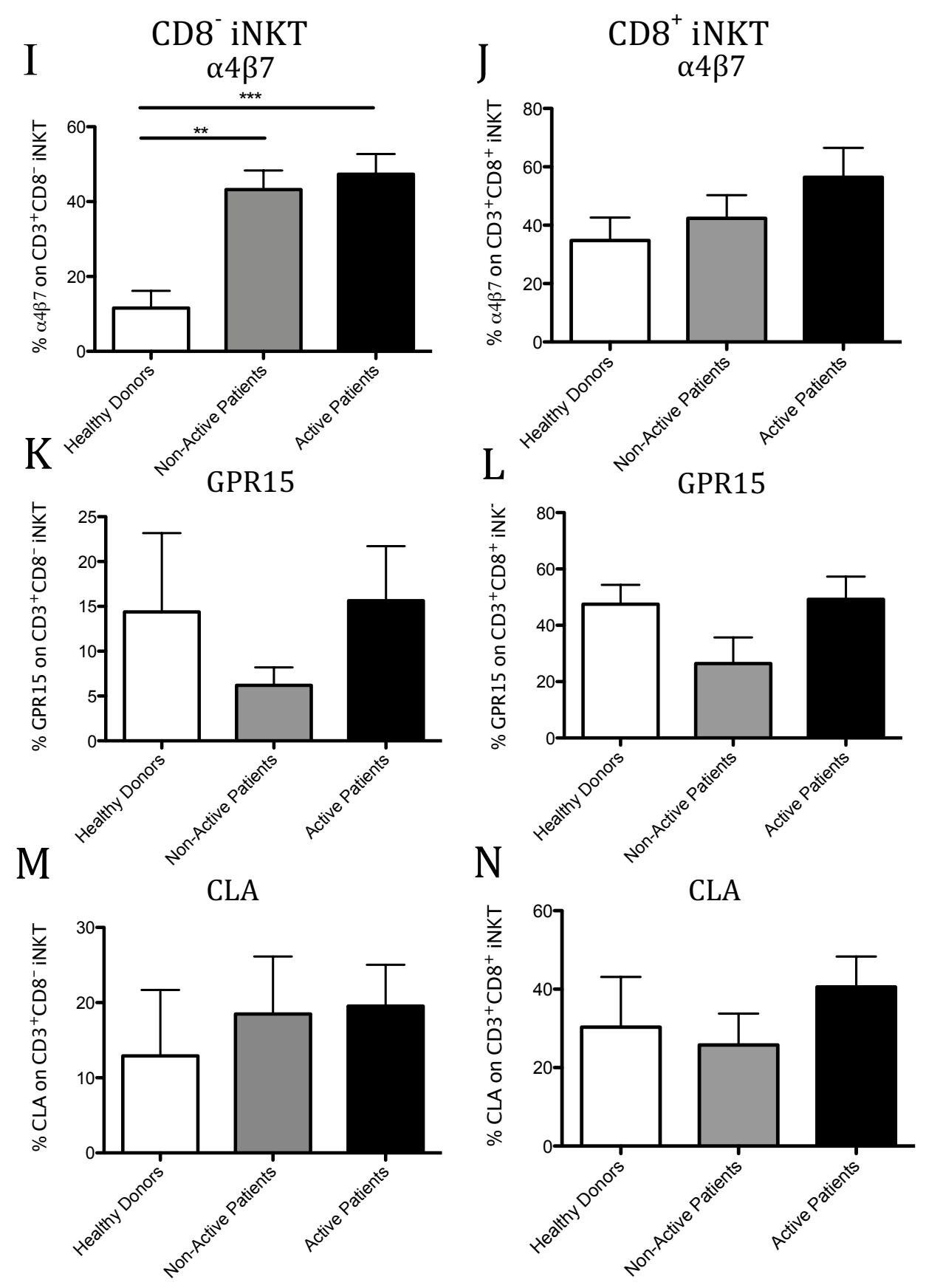

FIGURE 4. Continued. Single TR expression was analyzed for pooled groups of HDs, non-active Patients, and active patients on both iNKT subsets for (I, J) $\alpha 4 \beta 7$, (K, L) CLA and $(\mathbf{M}, \mathbf{N})$ GPR15.

$* * \mathrm{p}<0.005, * * * \mathrm{p}<0.0005$; t-test., ND means no data. 


\section{$\alpha 4 \beta 7$ Expression}

O P

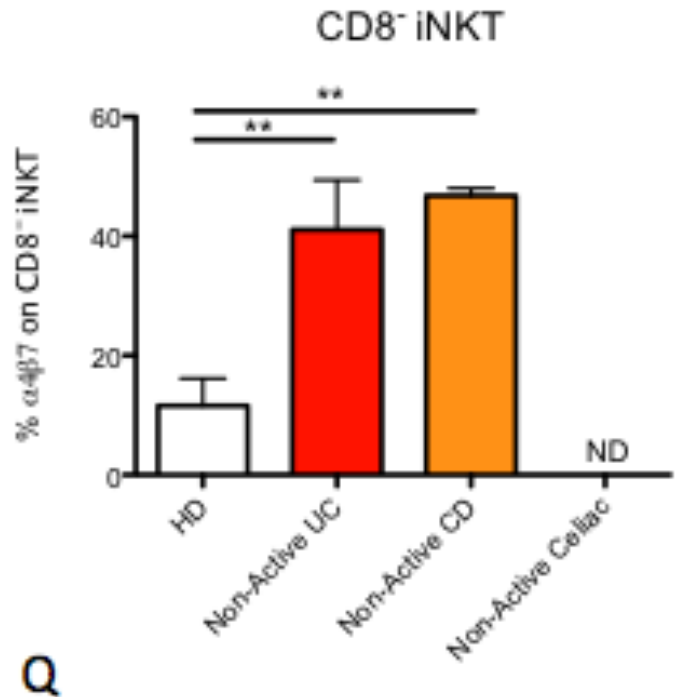

$\mathrm{CD}^{+}{ }^{+} \mathrm{NKT}$

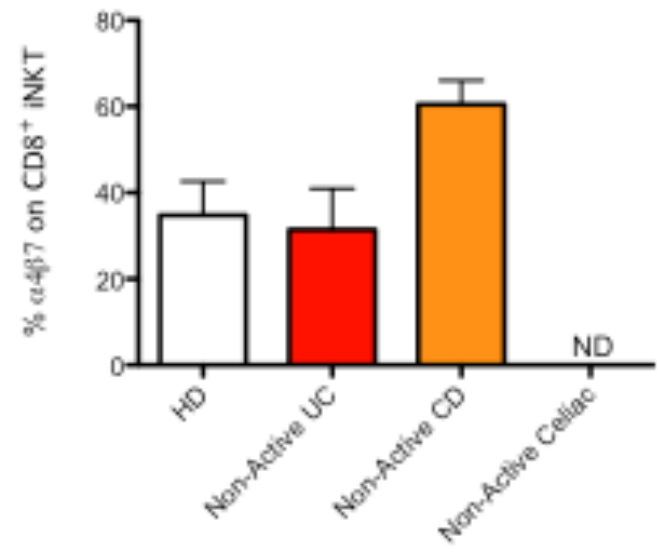

$P$

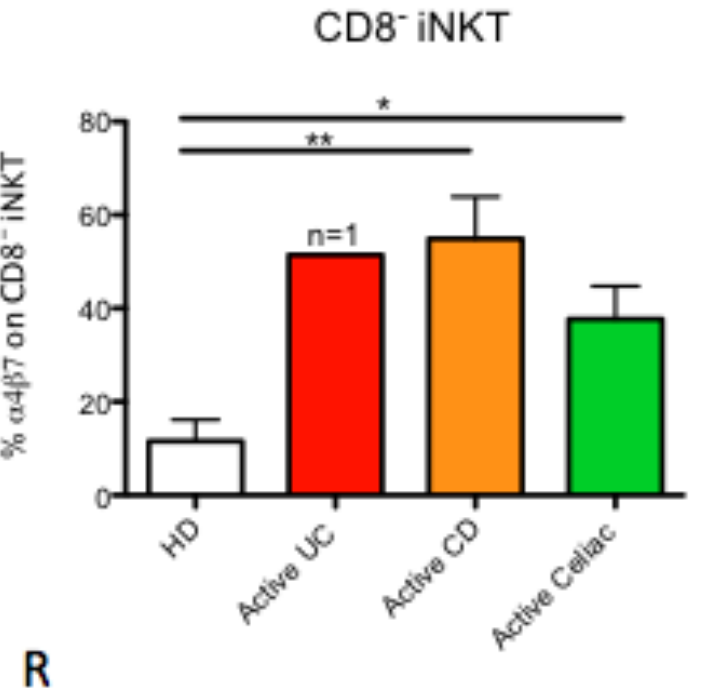

CD8* iNKT

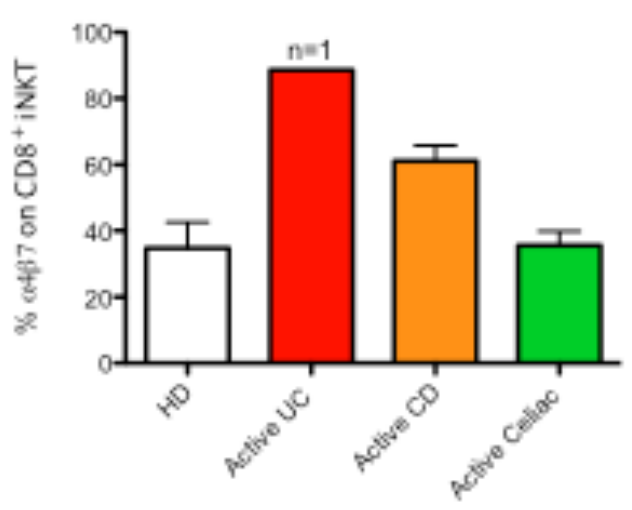

FIGURE 4. Continued. The single TR expression for $\alpha 4 \beta 7$ was further analyzed by disease and state on $(\mathbf{O}, \mathbf{P}) \mathrm{CD}^{+} \mathrm{CD}^{-}$and $(\mathbf{Q}, \mathbf{R}) \mathrm{CD}^{+} \mathrm{CD}^{+}$iNKT cells. ** $\mathrm{p}<0.005, * * * \mathrm{p}<0.0005$; t-test., ND means no data. 


\section{GPR15 expression}

$\mathrm{S}$
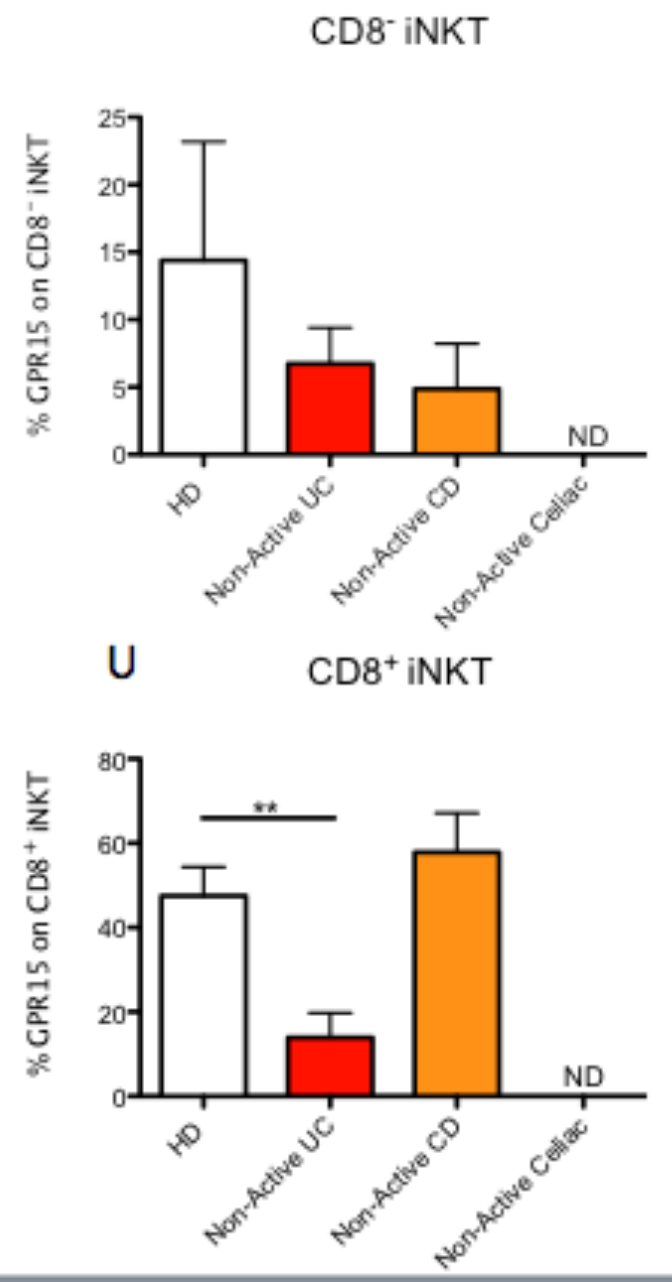

$\mathrm{T}$
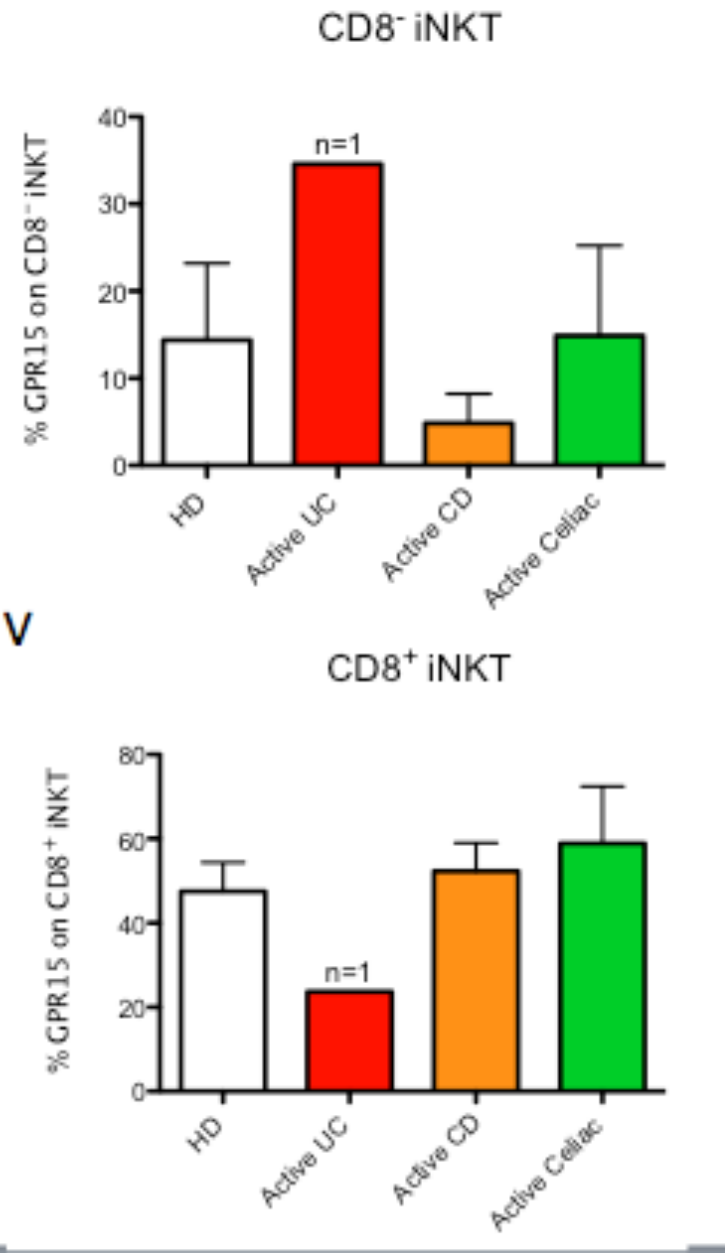

FIGURE 4. Continued. The single TR expression for GPR 15 was also analyzed by disease and state on $(\mathbf{S}, \mathbf{T}) \mathrm{CD}^{+} \mathrm{CD}^{-}$and $(\mathbf{U}, \mathbf{V}) \mathrm{CD}^{+} \mathrm{CD}^{+}{ }^{+}$NKT cells. $* * \mathrm{p}<0.005, * * * \mathrm{p}<0.0005$; t-test., ND means no data.

All patients were pooled and grouped into non-active or active state of disease according to their score regardless of disease type and compared to HDs. We observed an approximate 4-fold increase in the frequency of $\mathrm{CD}^{-}$iNKT cells that expressed TR $\alpha 4 \beta 7$ on both non-active $(43.2 \% \mathrm{p}=0.001)$ and active $(47.3 \% \mathrm{p}=0.001)$ patients compared to HDs (11.6\%)(Fig. 4I). There were no significant alterations in the frequency of the 
$\mathrm{CD}^{+}$iNKT population that express $\alpha 4 \beta 7$ between the various disease stages and HDs

(Fig. 4J). No significant changes were observed in non-active or active patient frequencies for both $\mathrm{CD}^{-}{ }^{-}$iNKT and $\mathrm{CD}^{+}{ }^{+}$iNKT cells expressing GPR15 and CLA compared to HDs (Fig. 4K-N).

In order to determine if there were any disease specific TR alterations, we analyzed the single expression of $\alpha 4 \beta 7$ and GPR15 on both iNKT subsets in patients with each disease and activity state. We saw a significant increase in the percentage of $\alpha 4 \beta 7$ expressing CD8 ${ }^{-}$iNKT cells in non-active UC (41.1\% p=0.008), non-active CD (46.8\% $\mathrm{p}=0.001)$ compared to HDs $(11.6 \%)$ (Fig. 40$)$, as well as active CD (54.9\% $\mathrm{p}=0.003)$, and active celiac $(37.7 \% \mathrm{p}=0.03)$ patients compared to HD’s (Fig. 4P). No significant increase in the $\alpha 4 \beta 7$ expressing $\mathrm{CD}^{+}$iNKT population was observed in all respective samples (Fig. 4Q and 4R).

GPR15 expressing CD8- iNKT cells only increased $(34.6 \% \mathrm{n}=1)$ in active UC compared to HDs (14.4\%)(Fig. 4T). Surprisingly, HDs had a relatively high percentage of GPR15 expressing CD8 ${ }^{+}$iNKT cells $(47.5 \%)$. The percentages of these cells decreased in both non-active UC (13.9\% p=0.006) (Fig. 4U) and active UC $(23.7 \% \mathrm{n}=1)$ when compared to HDs (Fig. 4V).

Frequency of double positive iNKT subsets expressing $\alpha 4 \beta 7$, CLA, or GPR15

We next wanted to distinguish the migratory fate of various iNKT cells by analyzing the expression of $\alpha 4 \beta 7^{+}$iNKT cells against those that migrate to the skin, CLA $^{+}$iNKT cells, by analyzing the simultaneous expression of GPR15.

We gated for $\mathrm{CD}^{-}$and $\mathrm{CD}^{+}$iNKT cells and recorded the frequency of cells that expressed both $\alpha 4 \beta 7$ and GPR15 to determine if these populations had a gut-homing 
migration specific to the large intestine (Fig. 5B and 5E). We compared and contrasted the mutually expressing $\alpha 4 \beta 7$ and GPR15 iNKT populations to those that expressed CLA and GPR15. A CLA ${ }^{+}$GPR $15^{+}$phenotype may be reflective of cell migration toward extraintestinal regions like the skin (Fig. 5C and 5F).
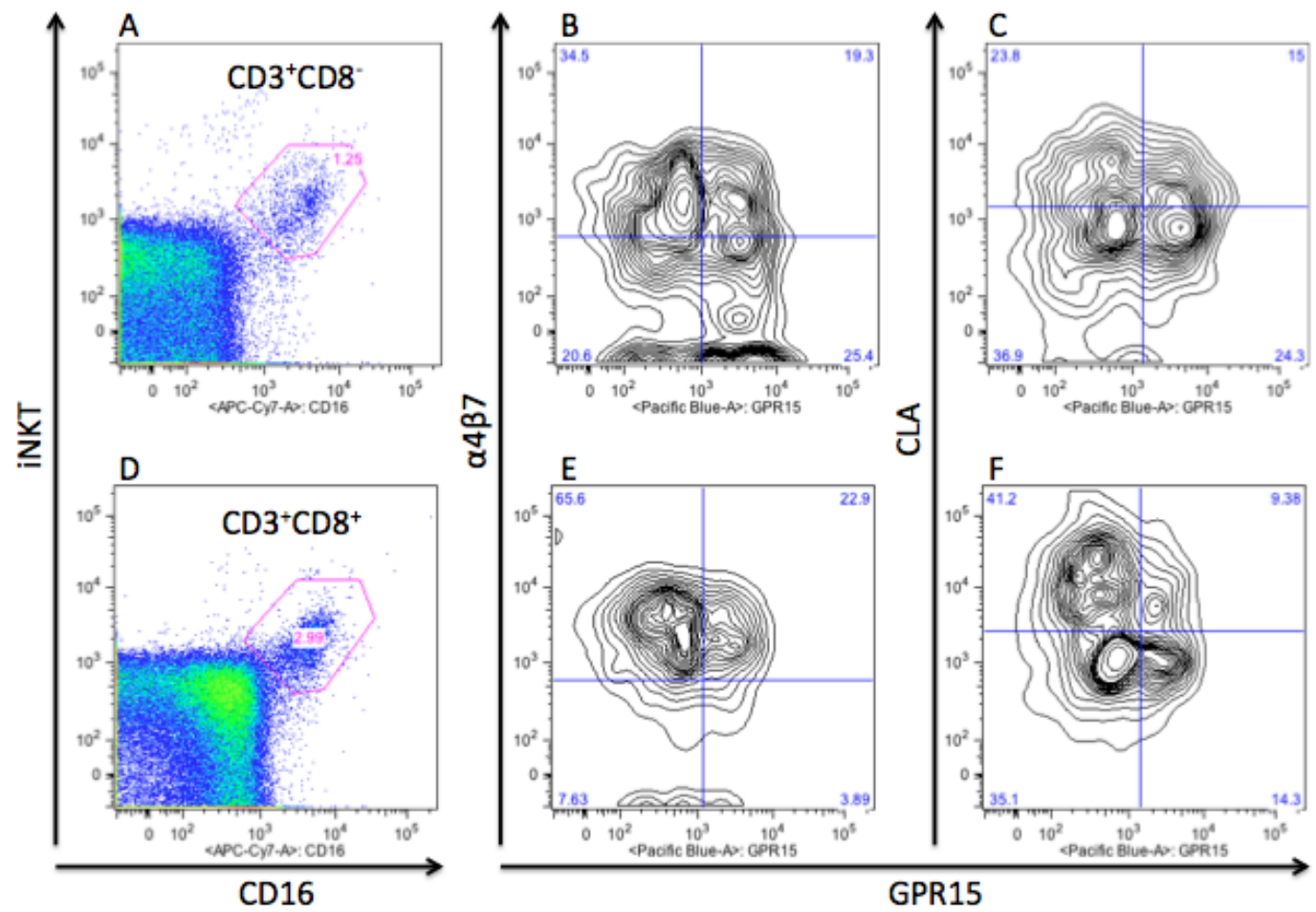

FIGURE 5. Double positive TR analysis on iNKT cell populations. Flow cytometry plots (sample 9 in Table 1) showing (A) $\mathrm{CD}^{+}{ }^{\mathrm{CD}} 8^{-}$iNKT subset and (B) its contour plot for $\alpha 4 \beta 7$ and GPR15 double positive population as well as (C) contour plot for CLA and GPR 15 double positive population. Similar gating strategy of (D) $\mathrm{CD} 3^{+} \mathrm{CD} 8^{+}$iNKT cells (E) for $\alpha 4 \beta 7$ and GPR15 double positive population and (F) for CLA and GPR15 double positive population. 

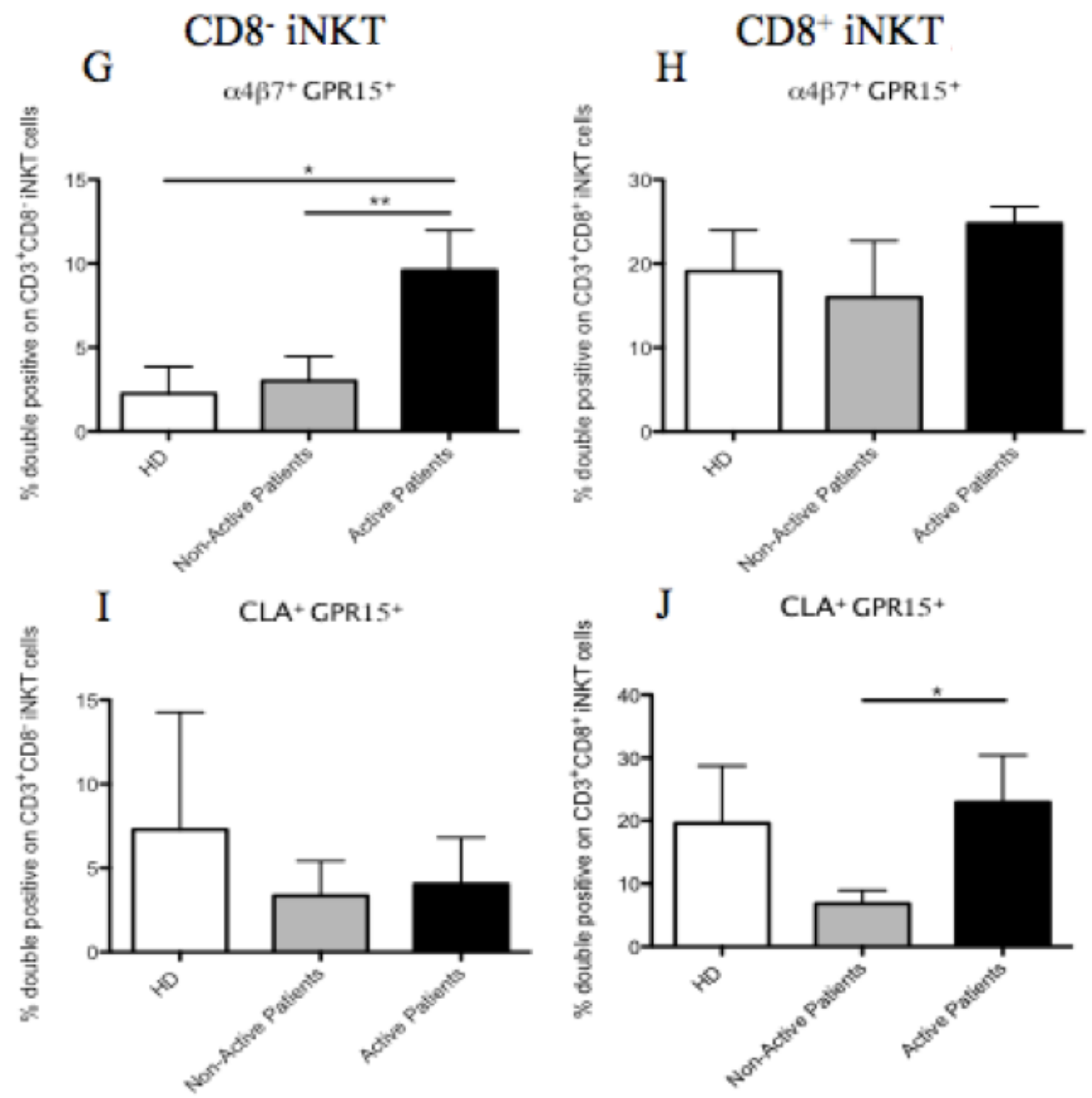

FIGURE 5. Continued. Mean percent of cells expressing (G) $\alpha 4 \beta 7$ and GPR15 on $\mathrm{CD}^{+} \mathrm{CD} 8{ }^{-}$iNKT and $(\mathbf{H}) \mathrm{CD}^{+} \mathrm{CD}^{+}$iNKT population. Mean percent of cells expressing (I) CLA and GPR15 on $\mathrm{CD} 3^{+} \mathrm{CD} 8{ }^{-}$iNKT and (J) $\mathrm{CD}^{+} \mathrm{CD} 8{ }^{+}$iNKT population. ${ }^{*} \mathrm{p}<0.05 * * \mathrm{p}<0.005$; t-test, ND means no data. 


\section{$\alpha 4 \beta 7$ and GPR15 double positive expression}
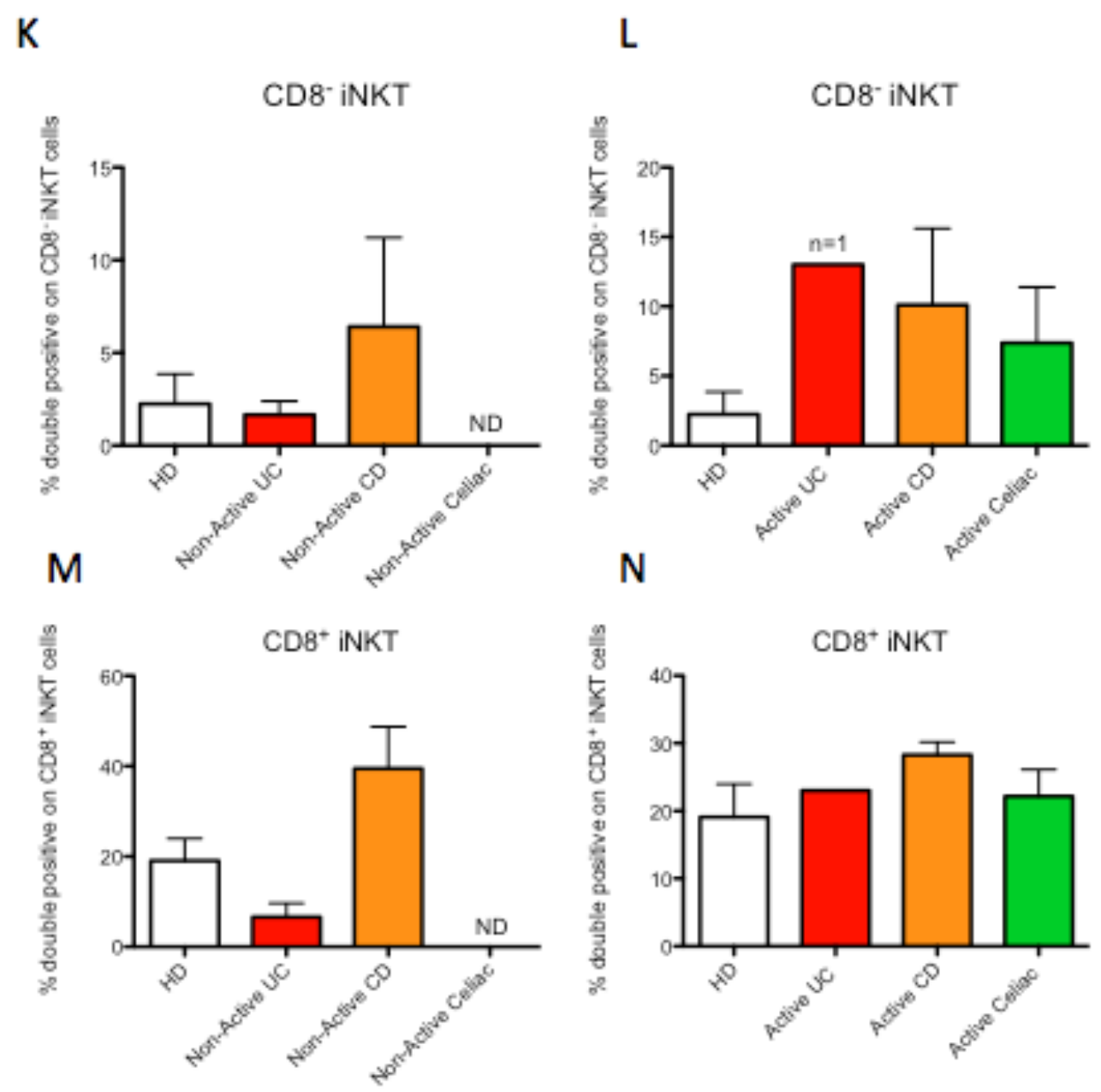

FIGURE 5. Continued. Further analysis of $\alpha 4 \beta 7$ and GPR15 double positive populations on $(\mathbf{K}, \mathbf{L}) \mathrm{CD}^{+} \mathrm{CD}^{-}$and $(\mathbf{M}, \mathbf{N}) \mathrm{CD}^{+} \mathrm{CD}^{+}$iNKT cells by disease and state.

$* \mathrm{p}<0.05 * * \mathrm{p}<0.005 ;$ t-test, ND means no data.

Again, all patients were pooled and grouped into non-active and active states of disease regardless of the disease type. There was a higher percentage of CD8 ${ }^{-}$iNKT cells expressing both the $\alpha 4 \beta 7$ and GPR15 in active patients (11.1\%) compared to non-active $(1.6 \%, p=0.002)$ patients and HDs $(2.2 \%, p=0.02)$ (Fig. $5 G)$. However, there was no 
significant increase in the respective $\mathrm{CD} 8^{+}$iNKT population (Fig. $5 \mathrm{H}$ ). In contrast, $25 \%$ percent of the CD8 ${ }^{+}$iNKT cells in active patients expressed both CLA and GPR15, which was increased approximately 3.7 -fold compared to non-active patients $(6.8 \%$ $\mathrm{p}=0.03$ ) (Fig. $5 \mathrm{~J}$ ) but, no significant differences were revealed in the frequency of CD8 ${ }^{-}$ iNKT cells which expressed CLA and GPR15 among all disease groups and HDs (Fig. $5 \mathrm{I})$.

We next recorded the frequency of the iNKT population expressing both $\alpha 4 \beta 7$ and GPR15 on patients grouped according to their disease and severity. Although additional patients are required to gain statistical confidence, our data showed that the frequency of $\alpha 4 \beta 7^{+}$GPR $15^{+}$expressing CD8 ${ }^{-}$iNKT cells may be higher in active UC patients $(13 \% \mathrm{n}=1)$ compared to HDs $(2.3 \%)$ (Fig. $5 \mathrm{~L})$. Our current data did not show a significant alteration in the percentage of $47^{+}$GPR $15^{+}$expressing CD $8^{+}$iNKT cells (Fig. $5 \mathrm{M}$ and $5 \mathrm{~N}$ ), or $\mathrm{CLA}^{+} \mathrm{GPR}^{+} 5^{+}$expressing $\mathrm{CD} 8^{-}$or $\mathrm{CD} 8^{+}$iNKT cells (data not shown).

Our data suggests a role for CD8 ${ }^{-}$iNKT cells expressing $\alpha 4 \beta 7$ and GPR15 to traffic to the gut and perhaps specifically the large intestine during active disease state. The frequency of $\mathrm{CD} 8^{+}$iNKT cells expressing CLA and GPR15 rose as well in active patients with chronic intestinal disease and the significance of that should be further studied.

\section{Discussion}

Circulating iNKT cells are increasingly recognized to be critical immunoregulators in patients with diseases that cause chronic inflammation due to their shared NK and T helper cell abilities to secrete pro and inflammatory cytokines (34). The identification of 
specific subsets of iNKT cells responding at various disease stages and the mechanisms of migration toward affected tissues are understudied. In this study, we characterized the frequency and TR phenotype of different subsets of a rare circulating T cell population during chronic intestinal inflammation. We focused on pediatric patients with a recent onset of IBD and celiac disease because these patients are less likely to be affected by other comorbidities and long-term medication use. We hypothesized that the frequency and TR expression of iNKT subsets would be altered in patients compared to healthy donors.

We studied two iNKT cell subsets, $\mathrm{CD} 8^{-}$and $\mathrm{CD} 8^{+}$iNKT cells. Our results showed that the frequency of both the $\mathrm{CD} 8^{-}$and $\mathrm{CD} 8^{+}$iNKT cell subsets was increased in all pediatric patients with chronic inflammation with both non-active and active disease states compared to HDs. This suggests that both iNKT subsets can reflect on a chronic disease which is not necessarily in an active state.

However, only CD8 ${ }^{-}$iNKT cells displayed an intestinal phenotype, as detected by the expression of $\alpha 4 \beta 7$, in all disease types, regardless of the disease severity. Furthermore, only CD8 ${ }^{-}$iNKT cells showed a large intestine phenotype, as detected by the expression of both $\alpha 4 \beta 7$ and GPR 15 , and only in the active UC patient, suggesting that this subset can be an indicator of current inflammation in the large intestine. ${ }^{5}$

These results imply that only the CD8- iNKT subset is reflective of intestinal inflammation and that GPR15 in conjunction with $\alpha 4 \beta 7$ is a favorable phenotype to detect current inflammation in the large intestine. In addition, characterizing markers of the small intestine, such as CCR9, in conjunction with $\alpha 4 \beta 7$ on CD8 ${ }^{-}$iNKT cells may detect inflammation in the small intestine. This phenotype may be useful in detecting

${ }^{5}$ Additional patients must be acquired to fully confirm this statement. 
small intestine associated inflammation as expected in CD and celiac disease. Also, additional analyses would be required to verify if the $\mathrm{CD}^{-}{ }^{-} \mathrm{iNKT}$ cell population increases during acute inflammation of the gut.

It is possible that the frequency of $\mathrm{CD}^{+}$iNKT cells that rise during chronic diseases but do not acquire an intestinal phenotype may be a general marker for chronic disease but not necessarily indicative to intestinal chronic inflammation. However, the rise in this subset that expressed both CLA and GPR15 suggests that this subset reflects extraintestinal inflammation.

Earlier work showed a decrease in circulating iNKT cells in adult celiac disease patients (55). However, insights gained by murine models about the crosstalk between microbiota and PB iNKT cells (40) showed that mice with altered early exposure to microbiota had an increase of circulating and mucosal iNKT cells compared to wild types and were more susceptible to severe colitis. It is possible that Grose's work was an observation of acute immune response while more recent work and this study focused on chronic inflammation of specified disease state. Another explanation for Grose's contrasting results may be that in his 23 adult samples, the iNKT cells were more deficient solely because iNKT cells decrease with age and may also become more deficient as a result (56). More samples must be collected to confirm the statistical significance and the moderate changes in iNKT frequency of our study.

In conclusion, our study demonstrated a significant increase in the frequency of two specific iNKT subsets, $\mathrm{CD}^{+}$and $\mathrm{CD}^{-}$, in the peripheral blood of patients with IBD and celiac disease at non-active and active disease states compared to HDs. Furthermore, we determined that based on TR expression of $\alpha 4 \beta 7$ and GPR15, CD8 ${ }^{-}$iNKT cells may 
have significant migration to the large intestine during intestinal disease that is not observed in $\mathrm{CD}^{+}{ }^{\mathrm{iNKT}}$ cells. We suspect that this $\mathrm{CD}^{-}{ }^{-}$iNKT migration to the large intestine is specific to UC patients; however, more samples are needed to confirm. Lastly, our data suggested that GPR15 in conjunction with CLA has extraintestinal migratory potential in humans that was not previously observed in mice due to the expression of CLA and GPR15 double positive populations in both iNKT subsets. Currently, our analysis may be used to define chronic intestinal inflammation in IBD and celiac disease patients. Further detailed characterization of specific subsets of iNKT cells may provide valuable tools to distinguish diseases and develop treatments. 


\section{References}

1. Sartor, R. B. (2006). Mechanisms of disease: Pathogenesis of Crohn's disease and ulcerative colitis. Nature Clinical Practice Gastroenterology \& Hepatology, 3(7), 390-407.

2. Luster, A. D., Alon, R., \& von Andrian, U. H. (2005). Immune cell migration in inflammation: Present and future therapeutic targets. Nature Immunology, 6(12), 1182-1190.

3. Schuppan, D., Popov, Y., \& Kornek, M. (2014). Methods and Compositions for Detecting and Treating Inflammatory Disease.

4. Loftus Jr, E. V. (2004). Clinical epidemiology of inflammatory bowel disease: Incidence, prevalence, and environmental influences. Gastroenterology, 126(6), 1504-1517.

5. Ivarsson, A., Myleus, A., Norstrom, F., van der Pals, M., Rosen, A., Hogberg, L., . . . Carlsson, A. (2013). Prevalence of childhood celiac disease and changes in infant feeding. Pediatrics, 131(3), e687-94. doi:10.1542/peds.2012-1015 [doi]

6. Kappelman, M. D., Moore, K. R., Allen, J. K., \& Cook, S. F. (2013). Recent trends in the prevalence of Crohn's disease and ulcerative colitis in a commercially insured US population. Digestive Diseases and Sciences, 58(2), 519-525.

7. Zawahir, S., Safta, A., \& Fasano, A. (2009). Pediatric celiac disease. Current Opinion in Pediatrics, 21(5), 655-660. doi:10.1097/MOP.0b013e32832f5b9d [doi]

8. Ludvigsson, J. F., Biagi, F., \& Corazza, G. R. (2014). Epidemiology of celiac disease. Celiac disease (pp. 27-37) Springer.

9. Ruemmele, F. M., Targan, S. R., Levy, G., Dubinsky, M., Braun, J., \& Seidman, E. G. (1998). Diagnostic accuracy of serological assays in pediatric inflammatory bowel disease. Gastroenterology, 115(4), 822-829.

10. O'Leary, C., Wieneke, P., Buckley, S., O'Regan, P., Cronin, C. C., Quigley, E. M., \& Shanahan, F. (2002). Celiac disease and irritable bowel-type symptoms. The American Journal of Gastroenterology, 97(6), 1463-1467.

11. Hüe, S., Mention, J., Monteiro, R. C., Zhang, S., Cellier, C., Schmitz, J., . . CerfBensussan, N. (2004). A direct role for NKG2D/MICA interaction in villous atrophy during celiac disease. Immunity, 21(3), 367-377.

12. Pascual, V., Dieli-Crimi, R., López-Palacios, N., Bodas, A., Medrano, L. M., \& Núñez, C. (2014). Inflammatory bowel disease and celiac disease: Overlaps and differences. World Journal of Gastroenterology: WJG, $20(17), 4846$.

13. H Bruining, D. (2012). Can radiology replace endoscopy in IBD? Current Drug Targets, 13(10), 1245-1247.

14. Baumgart, D. C., Bernstein, C. N., Abbas, Z., Colombel, J. F., Day, A. S., D'Haens, G., . . Kozarek, R. A. (2011). IBD around the world: Comparing the epidemiology, diagnosis, and treatment: Proceedings of the world digestive health day 2010Inflammatory bowel disease task force meeting. Inflammatory Bowel Diseases, 17(2), 639-644.

15. Hummel, T. Z. *., ten Kate, F. J. W. †., Reitsma, J. B. †., Benninga, M. A. *., \& Kindermann, A. (2012). Additional value of upper GI tract endoscopy in the diagnostic assessment of childhood IBD. Journal of Pediatric Gastroenterology \& Nutrition:, doi:10.1097/MPG.0b013e318243e3e3 
16. Gyires, K., Toth, E. V., \& Zadori, S. Z. (2014). Gut inflammation: Current update on pathophysiology, molecular mechanism and pharmacological treatment modalities. Current Pharmaceutical Design, 20(7), 1063-1081. doi:52834 [pii]

17. de Bie, C. I., Escher, J. C., \& de Ridder, L. (2012). Antitumor necrosis factor treatment for pediatric inflammatory bowel disease. Inflammatory Bowel Diseases, 18(5), 985-1002.

18. Bongartz, T., Sutton, A. J., Sweeting, M. J., Buchan, I., Matteson, E. L., \& Montori, V. (2006). Anti-TNF antibody therapy in rheumatoid arthritis and the risk of serious infections and malignancies: Systematic review and meta-analysis of rare harmful effects in randomized controlled trials. Jama, 295(19), 2275-2285.

19. Fiocchi, C. (1997). Intestinal inflammation: A complex interplay of immune and nonimmune cell interactions. American Journal of Physiology-Gastrointestinal and Liver Physiology, 273(4), G769-G775.

20. Mudter, J., \& Neurath, M. F. (2012). Insight into Crohn's disease pathomorphology. Abdominal Imaging, 37(6), 921-926. doi:10.1007/s00261-012-9885-3

21. Pene, J., Chevalier, S., Preisser, L., Venereau, E., Guilleux, M., Ghannam, S., . . . Gascan, H. (2008). Chronically inflamed human tissues are infiltrated by highly differentiated Th17 lymphocytes. Journal of Immunology, 180(11), 7423-7430.

22. Ghosh, S., \& Panaccione, R. (2010). Review: Anti-adhesion molecule therapy for inflammatory bowel disease. Therapeutic Advances in Gastroenterology, 3(4), 239258.

23. Tarlton, N. J., Green, C. M., Lazarus, N. H., Rott, L., Wong, A. P., Abramson, O. N., ... Abramson, T. (2012). Plasmablast frequency and trafficking receptor expression are altered in pediatric ulcerative colitis. Inflammatory Bowel Diseases, 18(12), 23812391.

24. Anderson, R. P., Degano, P., Godkin, A. J., Jewell, D. P., \& Hill, A. V. (2000). In vivo antigen challenge in celiac disease identifies a single transglutaminase-modified peptide as the dominant A-gliadin T-cell epitope. Nature Medicine, 6(3), 337-342.

25. Savilahti, E., Arato, A., \& Verkasalo, M. (1990). Intestinal $\gamma / \delta$ receptor-bearing T lymphocytes in celiac disease and inflammatory bowel diseases in children. constant increase in celiac disease. Pediatric Research, 28(6), 579-581.

26. Abadie, V., Discepolo, V., \& Jabri, B. (2012). Intraepithelial lymphocytes in celiac disease immunopathology. Paper presented at the Seminars in Immunopathology, 34(4) 551-566.

27. Benlagha, K., Wei, D. G., Veiga, J., Teyton, L., \& Bendelac, A. (2005). Characterization of the early stages of thymic NKT cell development. The Journal of Experimental Medicine, 202(4), 485-492. doi:jem.20050456 [pii]

28. Montoya, C. J., Pollard, D., Martinson, J., Kumari, K., Wasserfall, C., Mulder, C. B., ... Wilson, S. B. (2007). Characterization of human invariant natural killer T subsets in health and disease using a novel invariant natural killer T cell-clonotypic monoclonal antibody, 6B11. Immunology, 122(1), 1-14.

29. Moreira-Teixeira, L., Resende, M., Coffre, M., Devergne, O., Herbeuval, J. P., Hermine, O., . . L Leite-de-Moraes, M. C. (2011). Proinflammatory environment dictates the IL-17-producing capacity of human invariant NKT cells. Journal of Immunology (Baltimore, Md.: 1950), 186(10), 5758-5765.

doi:10.4049/jimmunol.1003043 [doi] 
30. Lee, P. T., Benlagha, K., Teyton, L., \& Bendelac, A. (2002). Distinct functional lineages of human V(alpha)24 natural killer T cells. The Journal of Experimental Medicine, 195(5), 637-641.

31. Zhong, X., \& Wu, J. (2014). TSC1 is critical for iNKT-cell terminal maturation and controls iNKT-1/17 balance (IRM7P. 490). The Journal of Immunology, 192(1 Supplement), 126.15-126.15.

32. Matsuda, J. L., Mallevaey, T., Scott-Browne, J., \& Gapin, L. (2008). CD1d-restricted iNKT cells, the 'Swiss-army knife' of the immune system. Current Opinion in Immunology, 20(3), 358-368.

33. YAO, C., JIANG, L., QIU, X., \& LI, B. (2011). CD3 CD56 NKT lymphocytes and CD3 TCRV $\alpha 24 \sim$ invariant NKT lymphocytes: Two different NKT cell subsets [J]. Current Immunology, 6, 012.

34. Emoto, M., Zerrahn, J., Miyamoto, M., Pérarnau, B., \& Kaufmann, S. H. (2000). Phenotypic characterization of CD8 NKT cells. European Journal of Immunology, $30(8), 2300-2311$.

35. Wen, X., Kim, S., Lawrenczyk, A., Xiong, R., Rao, P., Casorati, G., . . Yuan, W. (2014). A unique human-like CD8 iNKT cells in a humanized mouse model (APP2P. 113). The Journal of Immunology, 192(1 Supplement), 43.14-43.14.

36. Mangan, B. A., Dunne, M. R., O'Reilly, V. P., Dunne, P. J., Exley, M. A., O'Shea, D., ... Doherty, D. G. (2013). Cutting edge: CD1d restriction and Th1/Th2/Th17 cytokine secretion by human Vdelta3 T cells. Journal of Immunology (Baltimore, Md.: 1950), 191(1), 30-34. doi:10.4049/jimmunol.1300121 [doi]

37. Novak, J., \& Lehuen, A. (2011). Mechanism of regulation of autoimmunity by iNKT cells. Cytokine, 53(3), 263-270.

38. Han, A., Newell, E. W., Glanville, J., Fernandez-Becker, N., Khosla, C., Chien, Y. H., \& Davis, M. M. (2013). Dietary gluten triggers concomitant activation of CD4+ and CD8+ alphabeta T cells and gammadelta T cells in celiac disease. Proceedings of the National Academy of Sciences of the United States of America, 110(32), 1307313078. doi:10.1073/pnas.1311861110 [doi]

39. Montbarbon, M., Pichavant, M., Langlois, A., Erdual, E., Maggiotto, F., Neut, C., . . . Trottein, F. (2013). Colonic inflammation in mice is improved by cigarette smoke through iNKT cells recruitment. PloS One, 8(4), e62208.

40. Olszak, T., An, D., Zeissig, S., Vera, M. P., Richter, J., Franke, A., . . Blumberg, R. S. (2012). Microbial exposure during early life has persistent effects on natural killer T cell function. Science (New York, N.Y.), 336(6080), 489-493. doi:10.1126/science.1219328 [doi]

41. Bernardo, D., van Hoogstraten, I. M., Verbeek, W. H., Peña, A. S., Mearin, M. L., Arranz, E., . . . Bontkes, H. J. (2008). Decreased circulating iNKT cell numbers in refractory coeliac disease. Clinical Immunology, 126(2), 172-179.

42. Calleja, S., Vivas, S., Santiuste, M., Arias, L., Hernando, M., Nistal, E., . . de Morales, Jose G Ruiz. (2011). Dynamics of non-conventional intraepithelial Lymphocytes - NK, NKT, and $\gamma \delta \mathrm{T}$ - in celiac disease: Relationship with age, diet, and histopathology. Digestive Diseases and Sciences, 56(7), 2042-2049.

43. Vicente-Manzanares, M., \& Horwitz, A. R. (2011). Cell migration: An overview. Cell migration (pp. 1-24) Springer. 
44. Butcher, E. C., \& Picker, L. J. (1996). Lymphocyte homing and homeostasis. Science (New York, N.Y.), 272(5258), 60-66.

45. Sallusto, F. (2002). The role of chemokine receptors in primary, effector and memory immune response. Experimental Dermatology, 11(5), 476-478.

46. Luster, A. D., Alon, R., \& von Andrian, U. H. (2005). Immune cell migration in inflammation: Present and future therapeutic targets. Nature Immunology, 6(12), 1182-1190.

47. Yanai, H., \& Hanauer, S. B. (2011). Assessing response and loss of response to biological therapies in IBD. The American Journal of Gastroenterology, 106(4), 685 698.

48. Eksteen, B., \& Adams, D. H. (2010). GSK-1605786, a selective small-molecule antagonist of the CCR9 chemokine receptor for the treatment of crohn's disease. IDrugs : The Investigational Drugs Journal, 13(7), 472-781.

49. Berlin, C., Berg, E. L., Briskin, M. J., Andrew, D. P., Kilshaw, P. J., Holzmann, B., . . . Butcher, E. C. (1993). $\alpha 4 \beta 7$ integrin mediates lymphocyte binding to the mucosal vascular addressin MAdCAM-1. Cell, 74(1), 185-195.

50. Edinger, A. L., Hoffman, T. L., Sharron, M., Lee, B., O'Dowd, B., \& Doms, R. W. (1998). Use of GPR1, GPR15, and STRL33 as coreceptors by diverse human immunodeficiency virus type 1 and simian immunodeficiency virus envelope proteins. Virology, 249(2), 367-378.

51. Gibbons, D. L., Abeler-Dorner, L., Raine, T., Hwang, I. Y., Jandke, A., Wencker, M., ... Hayday, A. C. (2011). Cutting edge: Regulator of G protein signaling-1 selectively regulates gut $\mathrm{T}$ cell trafficking and colitic potential. Journal of Immunology (Baltimore, Md.: 1950), 187(5), 2067-2071. doi:10.4049/jimmunol.1100833 [doi]

52. Kim, S. V., Xiang, W. V., Kwak, C., Yang, Y., Lin, X. W., Ota, M., . . Littman, D. R. (2013). GPR15-mediated homing controls immune homeostasis in the large intestine mucosa. Science (New York, N.Y.), 340(6139), 1456-1459. doi:10.1126/science.1237013 [doi]

53. Collin, P., \& Reunala, T. (2003). Recognition and management of the cutaneous manifestations of celiac disease. American Journal of Clinical Dermatology, 4(1), 13 20.

54. Eksteen, B., Miles, A. E., Grant, A. J., \& Adams, D. H. (2004). Lymphocyte homing in the pathogenesis of extra-intestinal manifestations of inflammatory bowel disease. Clinical Medicine (London, England), 4(2), 173-180.

55. Grose, R. H., Cummins, A. G., \& Thompson, F. M. (2007). Deficiency of invariant natural killer T cells in coeliac disease. Gut, 56(6), 790-795. doi:gut.2006.095307 [pii]

56. Peralbo, E., Alonso, C., \& Solana, R. (2007). Invariant NKT and NKT-like lymphocytes: Two different $\mathrm{T}$ cell subsets that are differentially affected by ageing. Experimental Gerontology, 42(8), 703-708. 


\section{CHAPTER III: FUTURE EXPLORATIONS}

Further characterization of these cell subsets and their TR phenotypes may provide a more efficient form of distinguishing between $\mathrm{UC}, \mathrm{CD}$ and celiac disease and may potentially be used as a complementary approach to monitoring disease activity or therapeutic efficacy in pediatric patients.

Continued study of these cell subsets would include gathering more patient samples of each disease, especially celiac disease. Further, we would require observing samples from patients that are experiencing acute inflammation rather than a chronic disease state in order to verify the role of the iNKT cell subsets.

It would be imperative to look at TR markers for different regions of the intestine affected by these conditions, such as CCR9 for small intestine and CCR10 for colon. Moreover, to verify if iNKT subsets are mimicking the immune response of $\mathrm{T}$ helper cells, research including markers for Th1, Th2 and Th17 must be added to the flow cytometry analysis. This could include the addition of specific transcription factors such as RORYt, T-bet and GATA as well as relevant cytokines like IL-17, IFN-Y and IL-4, respectively.

Current flow cytometry technology has provided researchers the ability to observe many markers in one tube of blood, allowing for a more detailed characterization with a smaller starting sample. This work would benefit tremendously from the use of machines such as Cytof, which uses weighted isotopes and allows researchers up to 30 markers in one tube (23). Full characterization of rare subsets such as iNKT cells will be more comprehensive with continued application of these technologies. 